\title{
Early Marriage, Age of Menarche, and Female Schooling Attainment in Bangladesh
}

\section{Citation}

Field, Erica, and Attila Ambrus. 2008. Early marriage, age of menarche, and female schooling attainment in Bangladesh. Journal of Political Economy 116(5): 881-930.

\section{Published Version}

http://dx.doi.org/10.1086/593333

\section{Permanent link}

http://nrs.harvard.edu/urn-3:HUL.InstRepos:3200264

\section{Terms of Use}

This article was downloaded from Harvard University's DASH repository, and is made available under the terms and conditions applicable to Other Posted Material, as set forth at http:// nrs.harvard.edu/urn-3:HUL.InstRepos:dash.current.terms-of-use\#LAA

\section{Share Your Story}

The Harvard community has made this article openly available.

Please share how this access benefits you. Submit a story.

\section{Accessibility}




\title{
Early Marriage, Age of Menarche, and Female Schooling Attainment in Bangladesh
}

\author{
Erica Field and Attila Ambrus
}

Harvard University

\begin{abstract}
Using data from rural Bangladesh, we explore the hypothesis that women attain less schooling as a result of social and financial pressure to marry young. We isolate the causal effect of marriage timing using age of menarche as an instrumental variable. Our results indicate that each additional year that marriage is delayed is associated with 0.22 additional year of schooling and 5.6 percent higher literacy. Delayed marriage is also associated with an increase in use of preventive health services. In the context of competitive marriage markets, we use the above results to obtain estimates of the change in equilibrium female education that would arise from introducing age of consent laws.
\end{abstract}

\section{Introduction}

In much of the developing world, adolescent and child marriage continues to be a strong social norm, particularly for girls. Early female marriage is associated with a number of poor social and physical outcomes for young women and their offspring. On average, girls who marry as adolescents attain lower schooling, have lower social status in their husbands' families, report less reproductive control, and suffer higher rates of maternal mortality and domestic violence. ${ }^{1}$ In addition, these individual outcomes suggest a number of larger social consequences of early marriage, including higher population growth, more rapid spread of disease, and a higher incidence of orphans.

As a result of these patterns, governments in developing countries face increasing pressure to eradicate the practice with legal sanctions

${ }^{1}$ Jensen and Thornton (2003) provide a recent overview of these patterns worldwide.

[ Journal of Political Economy, 2008, vol. 116, no. 5]

(C) 2008 by The University of Chicago. All rights reserved. 0022-3808/2008/11605-0004\$10.00 
against parents who marry daughters before a standard age of consent. Proponents of age of consent laws argue that forcing parents to delay marriage will increase female schooling attainment and reproductive control and decrease the incidence of domestic violence, and social programs increasingly contain program rules designed to discourage the practice. For instance, a prominent micro-finance program in India excludes parents who marry daughters before 17 , and national education vouchers in Bangladesh exclude married girls. However, while statistics indicate that women who marry young fare worse, it is difficult to assess the extent to which these outcomes are driven by the timing of marriage as opposed to common factors related to poverty and traditional gender views that also hinder female advancement. Given that child marriage is most common in impoverished and culturally traditional settings, the observation that women who married young have on average less education does not imply that forcing girls to postpone wedlock would improve their outcomes.

This paper attempts to shed light on the issue by studying the schooling consequences of early marriage for girls in rural Bangladesh, an area with one of the highest rates of child marriage worldwide. Since it is also an environment of rapidly expanding schooling opportunities and returns to education for girls, adolescent marriage is frequently blamed for the persistent gender gap in schooling attainment. To estimate the influence of marriage practices on girls' schooling, we employ a two-step methodology. In the first step we measure changes in schooling investment that result from a random subset of girls being forced to postpone marriage. In particular, we make use of variation in the timing of menarche as an instrumental variable (IV) for age of first marriage. The idea behind this identification strategy is the following: While there are frequently incentives to marry daughters as young as possible, in Bangladesh as in many parts of the world, girls are typically withheld from the marriage market until the onset of puberty. This institutional feature in the context of high rates of very early marriage presents a binding constraint on exposure to adolescent marriage opportunities. In particular, natural variation in the timing of first menstruation within the age range of 11-16 generates quasi-random differences in the earliest age at which girls are at risk of marrying. ${ }^{2}$ Our estimates indicate that each additional year that menarche is delayed postpones marriage 0.74 year. This physical barrier to younger marriages, insofar as it is independent of schooling investment, presents a unique opportunity to assess the effects of child marriage on female education outcomes.

\footnotetext{
${ }^{2}$ See Palmert and Boepple (2001) for a discussion of distributions of age of menarche across populations.
} 
The validity of the IV strategy depends on potential unobservable differences in family background influencing both adolescent maturation and adult outcomes. Survey data on parents' wealth as well as adult height and health indicators reveal no significant differences in family background according to age of menarche within the age range to which we restrict our estimates. More important, this bias would work against our central findings. Hence, the results may underestimate parents' increase in schooling investment that arises from delayed marriage.

We also present evidence that reaching menarche indeed affects schooling through marriage decisions rather than through a direct effect by comparing the influence of delayed puberty on marriage and schooling according to sex-specific birth order. We show that, because of a traditionally strong preference for marrying daughters in order of birth, menarche has very little influence on marriage when a girl has many older sisters, and the influence of menarche on marriage declines continuously with sex-specific birth order conditional on the total number of female siblings. We then test whether the direct effect of menarche on schooling attainment follows a similar pattern according to sexspecific birth order. The logic here is that, while the number of older relative to younger sisters determines how quickly a girl can marry, it should not be related to religious or social attitudes of the girl's family that could induce them to take a daughter out of school after she reaches puberty. Hence, if the relationship between menarche and schooling is driven by parents' preference to remove girls from school at puberty, the influence of menarche on schooling attainment should be independent of birth order. Put differently, if the effect is driven by a change in female behavior at puberty, the treatment effect of puberty on schooling should vary across households on the basis of some characteristics such as religiosity, and not vary within households on the basis of individual characteristics such as birth order. Instead, the direct influence of menarche on schooling is nearly twice as large for eldest siblings and is sensitive to age gaps between female but not male siblings. We also show that the effect of menarche on schooling is independent of whether a woman follows restrictions on dress that traditionally begin at the onset of puberty. Hence, there is no evidence that our effects are disproportionately high among girls from more traditional or religious households, as would be anticipated if the effect were driven by adherence to social customs.

In the second stage of the analysis we show how the previous empirical results can be used for macro-level policy analysis. The IV estimates correspond to how a change in a woman's individual constraint affects her schooling attainment. In contrast, an age of consent law imposes a universal constraint on marriage choices, which gives rise to potentially complicated equilibrium adjustment effects with ambiguous direction 
of influence. The regulation induces a change in the equilibrium amount of monetary transfers that brides of different ages have to pay when they marry, which in turn can change marriage age decisions of even those women who were not directly affected by the change (who in the absence of regulation would have married at an older age). However, we provide a simple condition on preferences under which the equilibrium adjustment is very simple: those women who would marry younger than the minimum legal age in the absence of regulation marry exactly at the minimum legal age if the restriction is imposed, whereas the marriage age decisions of all other women are unaffected. The condition requires that women can be ordered with respect to their incremental utilities from marrying a year later and men can be ordered with respect to their incremental (dis)utilities from marrying a bride who is a year older, a plausible assumption in the setting under study. The resulting equilibrium adjustment procedure implies that our empirical estimates can be used to predict the impact of age of consent laws since the effect of a universal constraint on a woman's marriage age is identical to her facing the same individual constraint.

The results we obtain indicate that female schooling is substantially constrained by marriage opportunities at young ages. A 1-year postponement of marriage between the ages of 11 and 16 increases schooling by an estimated 0.22 year and adult literacy by 5.6 percent. Correspondingly, at the aggregate level we estimate that legally restricting marriages below age 17 would increase average female schooling by a minimum of 0.56 year, or 9 percent. The individual effect of postponement is substantially higher below age 16 than above, but at the aggregate level, this is partially offset by the fact that for each additional year there are more individuals who are not biologically constrained: A universal constraint on marriages below 16 would increase average schooling by only 0.22 year. In addition to increasing education, later marriage is associated with significant improvements in utilization of prenatal care services. Since these gains are independent of schooling attainment, they indicate an important age effect of marrying late in addition to the potential impact of education on health behavior.

Our approach fills an important gap in the existing literature on marriage institutions in developing countries by generating possibly the first estimates of the causal effect of child marriage on female schooling and the predicted impact of age of consent laws. While there is a small literature that investigates the correlates of marriage age, little research has examined the direct influence of early marriage, presumably because of the difficulty of finding exogenous variation in institutional rules. The methodology we introduce to predict equilibrium responses from reduced-form estimates can potentially be used in other settings 
to assess the impact of imposing constraints on transactions in a competitive market.

\section{Motivation}

The gender gap in schooling attainment remains high in many parts of the developing world, even in settings in which the economic returns to schooling appear to be as large for women as for men (or larger) or the direct costs are lower (Schultz 1987). For instance, in Bangladesh, only 56 percent of women between the ages of 25 and 30 in 1996 completed primary school (grade 5) relative to 77 percent of men in their cohort, and more than twice as many boys as girls enrolled in grade 10 (Khandker and Samad 1995; Bruce, Hewett, and Lloyd 2001). Particularly striking is the fact that even in recent years when the government of Bangladesh has provided a universal stipend for female secondary school that covers the bulk of the direct costs of education for girls but not for boys, the attainment gap has persisted. Although girls and boys are now equally likely to enroll in secondary school, girls drop out by grade 11 (age 16) at five times the rate of boys. ${ }^{3}$

In settings such as Bangladesh, traditional customs that sanction adolescent marriage are frequently blamed for low female schooling attainment because they raise the opportunity cost of educating girls. As summarized in the Mahmud's report, "the pressure for early marriage remains a powerful force that shapes the alternatives girls have and constrains their access to secondary education" (Mahmud 2003). However, while it is true that child marriage and low female schooling attainment go hand in hand since girls rarely continue school once they are married, this by itself reveals little about the degree to which parents' choices are constrained by marriage opportunities and hence the added schooling that girls would receive if the practice were abolished.

For a number of reasons, laws that encourage girls to postpone marriage may not improve their schooling outcomes or overall well-being. First, parents' motives for marrying daughters at young ages are often strongly related to economic circumstances of the family. In addition to removing the economic burden on their parents' household, younger brides typically attain higher-status husbands with lower dowries. Hence, families that choose this path may be those that are unable to provide for their daughters or care least about their welfare. Higher education may further increase the price a girl has to pay for a spouse if social norms require that husbands have higher education levels than wives, giving further disincentive for parents to invest in daughters' schooling

\footnotetext{
${ }^{3}$ In particular, according to a recent project evaluation, female students constituted 48 percent in grades 6-10 but only 13 percent in grades 11-12 (Mahmud 2003).
} 
before marriage. In contrast, a girl's education is rarely valued in traditional marriage markets and so would not directly improve her choice set. Second, delaying marriage might not increase girls' education because of lack of schooling opportunities, in which case forcing girls to marry later might cause them to be sent into the labor force to provide for their families and cover the increased cost of marriage.

In what follows we focus on the question of how age of consent laws would affect female education, and we restrain from interpreting the results in a formal welfare analysis. The reason is mainly that the data available to us do not provide sufficient information for such an analysis. First of all, in most cases of adolescent marriage, the relevant decision makers are parents or caretakers, and we cannot assess the extent to which they internalize the interests of their children. For example, if parents are not fully altruistic and marriage is costlier for girls who marry later, then girls end up marrying inefficiently early. Even if parents try to incorporate their daughters' interests into marriage decisions, they might make systematic errors, for example, underestimating the value of education. Second, it is difficult to quantify the positive externalities of an increase in female education in Bangladesh. Third, if an age of consent law affects the level of dowries in the marriage market, then a welfare analysis would need to take into account the induced changes in household consumption.

\section{Data and Methods}

\section{A. Setting}

We examine the causal effect of adolescent marriage among a representative sample of women in Matlab, a relatively impoverished region of rural Bangladesh. The setting is appropriate given low levels of average schooling and marriage age. Nationwide, only about 70 percent of children in Bangladesh enroll in primary school, of which almost two-thirds drop out before completing the 5-6-year cycle. Bangladesh also has one of the lowest adult literacy rates in the world, averaging around 30 percent for adults over 40 and only 22 percent for women. In addition, early marriages are customary for female adolescents throughout rural Bangladesh, almost all of which are arranged by parents. ${ }^{4}$ The International Centre for Research on Women's Demographic Health Survey, 1996-2001, lists Bangladesh as the country with the second-highest rate of child marriage, with an estimated 75 percent of girls married before they reach age 18 (ICRW 2003). In response to the problem, the government has attempted on several occasions to institute

\footnotetext{
${ }^{4}$ In Matlab, only 1.6 percent of women under 44 report independently selecting their spouse (1996 data from the Matlab Health and Socioeconomic Survey [MHSS]).
} 
age of consent laws, none of which have had a discernible effect on marriage practices in rural areas. ${ }^{5}$ While the country has witnessed a gradual increase in the average age of female marriage of approximately 3 years over the past quarter century, a significant fraction of girls continue to marry below the age of $16 .^{6}$

An important feature of local marriage markets is the dowry system. Although dowries are currently illegal in Bangladesh, they are prevalent among Muslims and Hindu families alike. In the MHSS data, roughly two-thirds of recent brides (under age 30) report some amount of dowry given to their husbands' families at marriage. Dowry is typically under control of the woman's husband and in-laws, and it can be difficult for a woman to secure for her own use should the marriage terminate (Bates et al. 2004).

\section{B. Data}

Data for the analysis come from the 1996 MHSS. The primary survey consists of household- and individual-level information on 4,364 households clustered in 2,687 baris, or residential compounds, an approximate one-third random sample of the total number of baris in the surveillance area (Rahman et al. 1999). The primary sampling unit of the MHSS was the bari, a cluster of extended families that functions as the basic unit of economic activity, landholding, and social identity. In each bari a maximum of two households were selected for interview. Within households, all individuals over 55, the head, spouse, and parents of the head, and a random sample of other members between 15 and 49 were interviewed.

The MHSS data are ideal for implementing our identification strategy. First, detailed economic and demographic data were collected at the individual, household, and village levels. In particular, each ever-married woman was asked to provide complete schooling, marital, and reproductive histories, including the timing of menarche, age at first marriage, and outcome of all pregnancies. An important advantage of the data is the fact that survey reports of births and marriages could be cross-checked with vital statistics information, including marriage and birth records from the regional Demographic Surveillance System

\footnotetext{
${ }^{5}$ Arends-Kuenning and Amin (2004) report that the series of child marriage acts in Bangladesh, which gradually increased the legal age of marriage from 12 to 18 , had almost no effect on the timing of marriage for rural households other than to encourage misreporting on marriage documents.

${ }^{6}$ An estimated 75 percent of rural girls in Bangladesh marry before the age of 16 (Barkat and Majid 2003).
} 
(DSS), minimizing concern over recall bias and misreporting. ${ }^{7}$ All sample members were also asked about current health status, and survey takers collected on site anthropometric measures including height and weight. Information on family background was collected in a survey module pertaining to sample members' parents, and currently married women were asked about details of their married life and health behaviors.

\section{Sample Construction}

We limit our sample to the 2,101 ever-married women between the ages of 25 and 44 who have nonmissing data for our outcomes of interest, excluding women in the Determinants of Natural Fertility Survey subsample. The left-hand cutoff point was chosen to minimize censoring of women who marry for the first time late in life while retaining the largest possible share of the sample. Of the women in our sample, 95.5 percent are currently married, 3.1 percent are unmarried widows, and 1.4 percent are unmarried divorcees.

Summary statistics for the sample are presented in table 1, divided according to age of marriage and age of menarche. The data reflect the national patterns of low female marriage age, schooling, and literacy and high fertility. The median age of first marriage is 15 , and the sample has extremely low levels of education and literacy. Among those who ever attended school, 41 percent cite marriage as the primary reason for dropping out. Roughly one-third of the women in the sample report some form of subservience to their spouse or in-laws, as indicated by being prevented from leaving the house for work or family visits or having money or possessions taken from them, although the majority report participating in family decisions.

As reported in columns 2 and 3, differences in schooling outcomes between women who marry early and those who marry late are consistent with the global trends: the literacy rate among women who married before age 16 is only 60 percent that of women who marry later, and schooling attainment is 1.3 years lower. The fact that father's and mother's schooling and own school enrollment at age 9 are also significantly higher for women who marry later indicates important unobservable differences between these subsamples confounding ordinary least squares (OLS) estimates of the relationship between marriage age and adult outcomes.

\footnotetext{
${ }^{7}$ Note that approximately 25 percent of sample members born outside of the region are absent from birth records, and marriage records are missing for at least 5 percent of those who married prior to 1973 .
} 


\section{Estimation Strategy}

To assess the causal effect of early marriage on female schooling, we use age of menarche as an IV for marriage age. As demonstrated in numerous medical studies, the transition from childhood to reproductive age in normal, healthy adolescents occurs across a wide range of ages in any population (Scott and Johnston 1985; Cambridge Encyclopedia of Growth and Development 1998). In Bangladesh, where age at first marriage is traditionally bounded below by menarche, these differences generate exogenous variation in girls' risk of marrying young (Begum 2003). Although informal prearrangements may be made when children are young, it is relatively rare to enter a girl into an official union before she has reached puberty. ${ }^{8}$ Meanwhile, menarche generates a strong shift in parents' demand to marry daughters. As explained by Begum, "In Bangladeshi society a teenage daughter reaching menstruation becomes a burden for many parents because preservation of her virginity is the greatest concern for a bride. As a result . . . parents like to get their daughters married as early as possible" $(2003,86)$.

For the most part, the MHSS data reflect these patterns. Columns 46 of table 1 report the mean ages at first marriage corresponding to each year of menarche in the sample, also illustrated in figure 1. Over 70 percent of first marriages take place within 2 years of menarche. Less than 18 percent of women report prepubescent marriages, and the majority (68 percent) of these cases are those in which marriage precedes menarche by 1 year. As evident in figure 1, after age 13 the timing of first marriage climbs steadily with the onset of puberty. Figure 2 shows the distributions of age of marriage and menarche, revealing a significant symmetric shift in the timing of marriage with each tercile of menarcheal age.

The IV approach involves estimating a two-stage model of the following form, where $Y_{i}$ is the outcome of interest, $A_{i}$ is individual $i$ 's age at marriage, and $Z_{i}$ is $i$ 's age at menarche, the instrument used to identify the first-stage equation:

$$
Y_{i}=\alpha_{0}+\alpha_{1} A_{i}+\alpha_{2}^{\prime} X_{i}+v_{i}
$$

and

$$
A_{i}=\beta_{0}+\beta_{1} Z_{i}+\beta_{2}^{\prime} X_{i}+\nu_{i} .
$$

In all the estimates, $X_{i}$ includes the following set of controls: adult height, family background and family composition characteristics, religion, and a dummy variable indicating whether the woman currently

\footnotetext{
${ }^{8}$ Bullough $(1981,366)$ reports that "in Islamic countries it was criminal to have sexual relations with a woman before she had menstruated. Before a marriage . . . women were to examine the girl to see that she was physically prepared."
} 


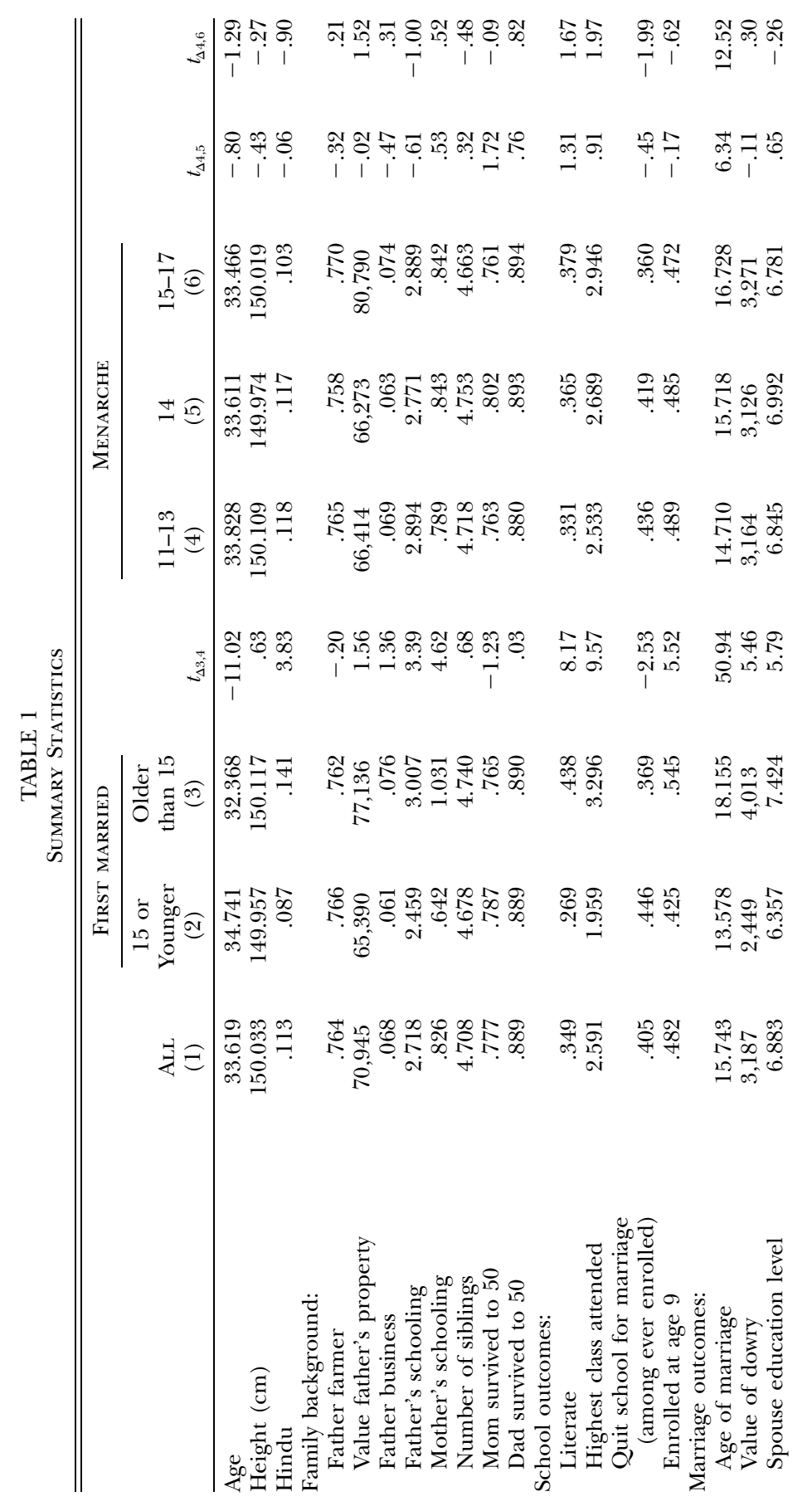




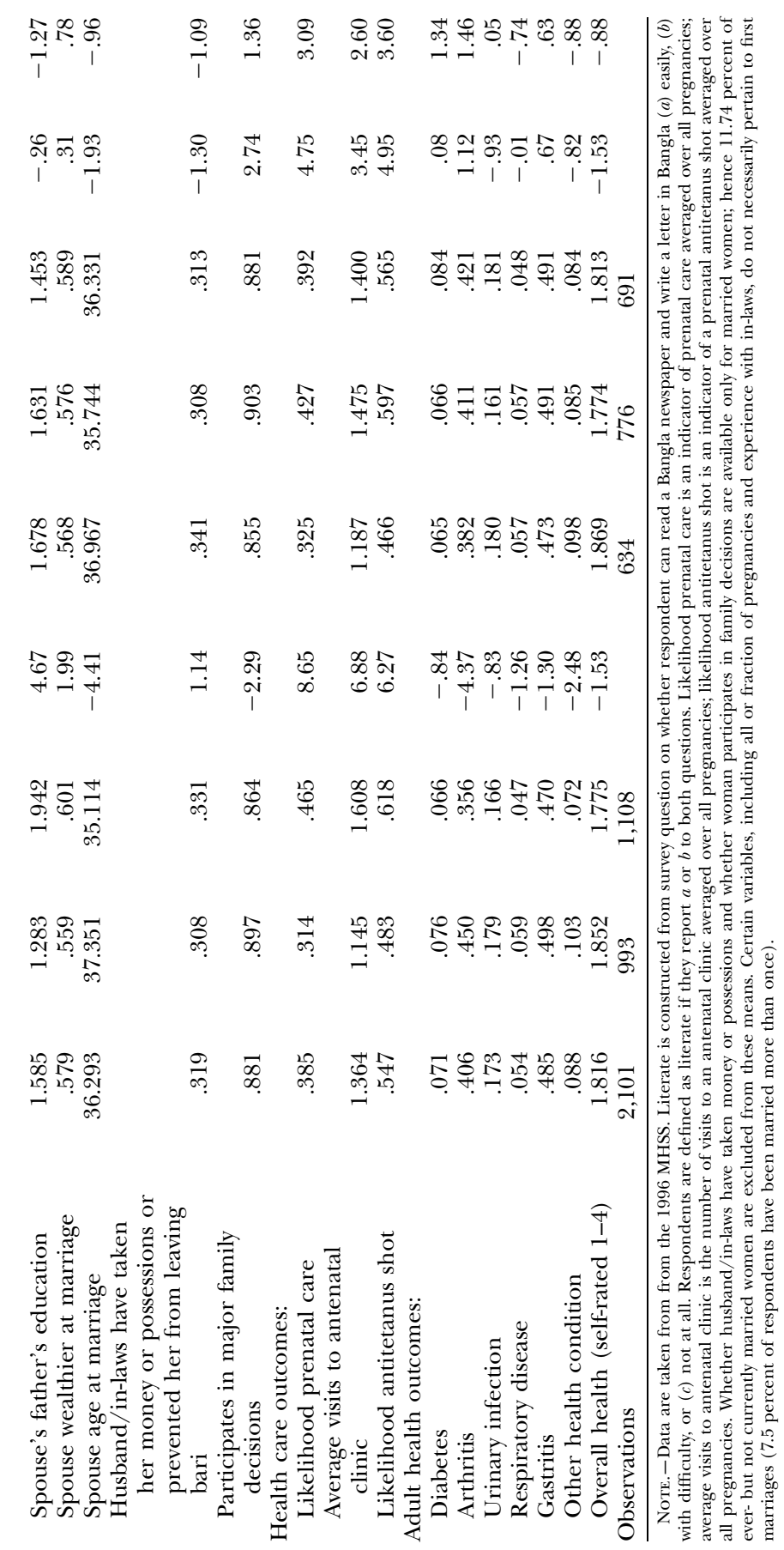




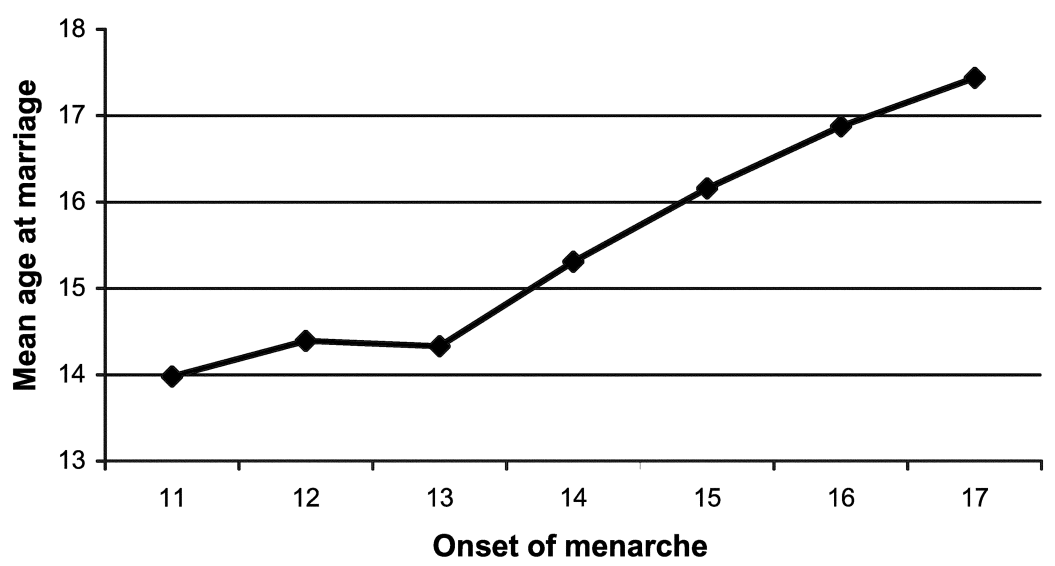

Fig. 1.-Age of menarche and age of first marriage. Data are taken from the 1996 MHSS. The sample includes ever-married women between 25 and 45 with nonmissing values for age at marriage and age at menarche who reached menarche between 11 and 17.

resides in a district of Matlab that is part of the treatment region for the national fertility intervention. Family background characteristics include father's and mother's education, whether father owned farmland or a family business, value of father's property, number of siblings, number of female siblings, whether mother and father survived to age 50, and whether the individual was enrolled in school at age 9. As detailed in Joshi (2004), economic circumstances of the family, including whether a girl's father was alive at marriage, are strong predictors of marriage market outcomes in the MHSS sample. ${ }^{9}$ We also include 5year age intervals and a linear time trend for age.$^{10}$ Robust standard errors are used in the analysis to correct for clustering at the bari level.

Identification of the IV model requires a strong correlation between age of menarche and age of first marriage. As the pattern in figure 1 illustrates, this requirement is well satisfied in the MHSS data. Results from the first-stage regression with and without the full set of controls and village fixed effects are presented in table 2. For the base specification with full set of controls (col. 3), every additional year that puberty is delayed, marriage is postponed an estimated 0.74 year, with a standard error of 0.06 and an F-statistic of 146. Column 2 allows for nonlinearity

\footnotetext{
${ }^{9}$ Dummy indicators of whether parents were alive at marriage produce similar results to mortality by age 50 but are arguably less exogenous to marriage timing.

${ }^{10}$ All estimates are also run with single year of birth fixed effects and dummy indicators of village of residence. The point estimates throughout are robust to this specification, although the table 6 results lose statistical significance when both sets of fixed effects are included.
} 

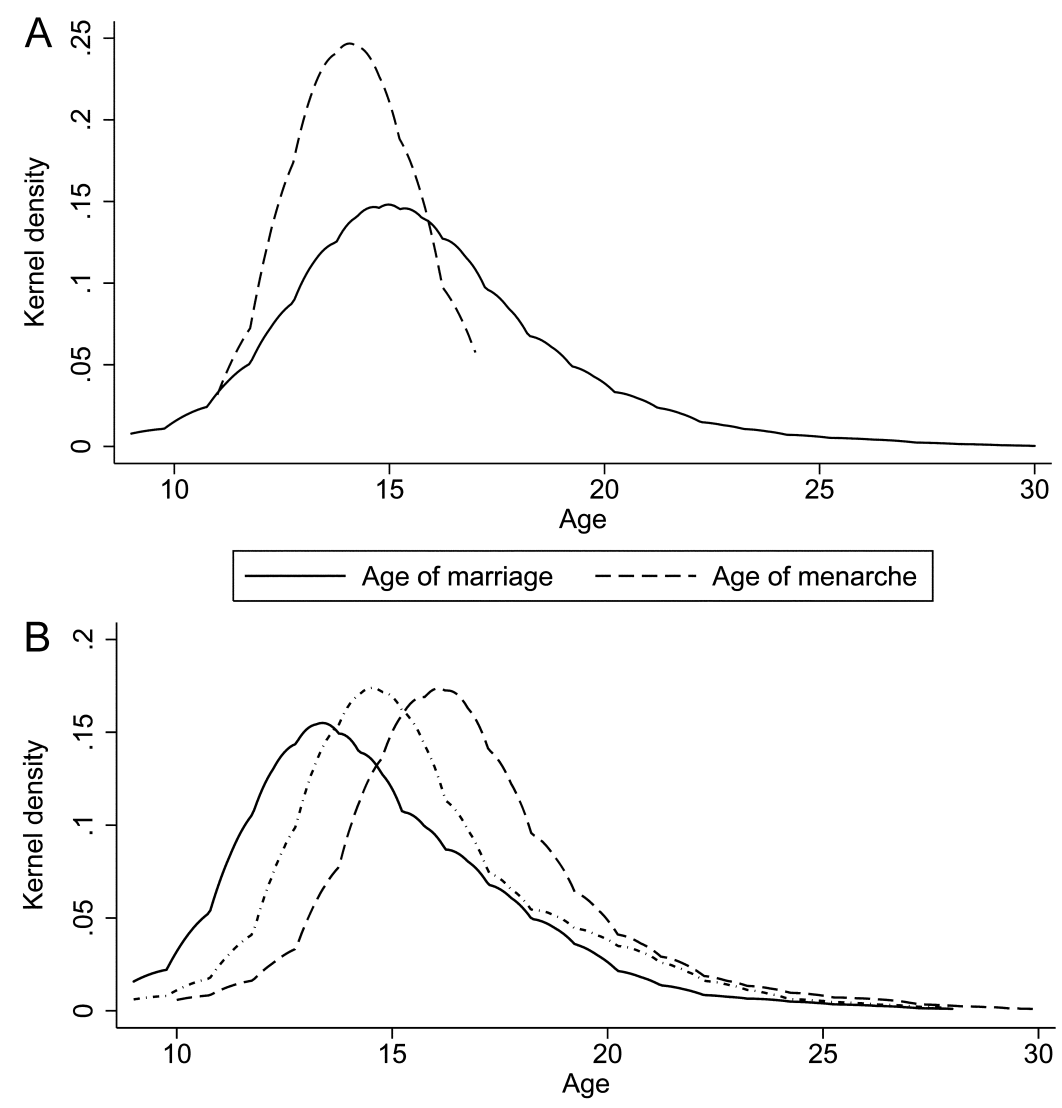

\begin{tabular}{llll}
\hline Menarche ages $10-13$ & $\ldots \ldots \ldots$ & Menarche age 14 \\
---- Menarche ages $15-17$ &
\end{tabular}

FIG. 2.-A, Age of menarche and marriage. $B$. Age of marriage by age of menarche group. Data are taken from the 1996 MHSS. The sample includes ever-married women between 25 and 45 with nonmissing values for age at marriage and age at menarche who reached menarche between 11 and 17. Epanechnikov kernel, bandwidth $=1$.

in the effect of menarche on marriage by including dummy indicators of menarcheal age. Throughout the analysis, results are presented with the specification of column 3 but are universally robust to a nonlinear first-stage regression and village fixed effects (col. 6). 
TABLE 2

First-Stage Regression: Age of First Marriage

\begin{tabular}{|c|c|c|c|c|c|c|}
\hline & (1) & (2) & (3) & (4) & (5) & (6) \\
\hline Age of menarche & $\begin{array}{l}.743 \\
(.063)^{* *}\end{array}$ & & $\begin{array}{l}.738 \\
(.061)^{* *}\end{array}$ & $\begin{array}{l}.803 \\
(.065) * *\end{array}$ & $\begin{array}{l}.682 \\
(.087) * *\end{array}$ & $\begin{array}{l}.789 \\
(.088) * *\end{array}$ \\
\hline Menarche 11 & & $\begin{array}{l}-3.803 \\
(1.015) * *\end{array}$ & & & & \\
\hline Menarche 12 & & $\begin{aligned}- & 2.219 \\
& (.384) * *\end{aligned}$ & & & & \\
\hline Menarche 13 & & $\begin{array}{r}-2.534 \\
(.245) * *\end{array}$ & & & & \\
\hline Menarche 14 & & $\begin{array}{rl}-1 & 1.485 \\
& (.232) * *\end{array}$ & & & & \\
\hline Menarche 15 & & $\begin{array}{l}-.685 \\
(.245) * *\end{array}$ & & & & \\
\hline Height $(\mathrm{cm})$ & & & $\begin{array}{l}.010 \\
(.012)\end{array}$ & $\begin{array}{l}.009 \\
(.012)\end{array}$ & $\begin{array}{l}.008 \\
(.015)\end{array}$ & $\begin{array}{l}.007 \\
(.017)\end{array}$ \\
\hline Age & & & 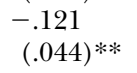 & $\begin{array}{l}-.134 \\
(.044) * *\end{array}$ & $\begin{array}{l}-.175 \\
(.065) * *\end{array}$ & $\begin{array}{c}-.058 \\
(.059)\end{array}$ \\
\hline Value father's & & & & & & \\
\hline property & & & $\begin{array}{r}-.001 \\
(.034)\end{array}$ & $\begin{array}{r}-.019 \\
(.036)\end{array}$ & $\begin{array}{c}-.004 \\
(.043)\end{array}$ & $\begin{array}{r}-.018 \\
(.051)\end{array}$ \\
\hline Contraceptive & & & & & & \\
\hline intervention & & & $\begin{array}{l}.255 \\
(.125)^{*}\end{array}$ & $\begin{array}{l}1.69 \\
(1.762)\end{array}$ & $\begin{array}{l}.141 \\
(.182)\end{array}$ & $\begin{array}{l}.354 \\
(.173) *\end{array}$ \\
\hline Father business & & & $\begin{array}{c}-.091 \\
(.230)\end{array}$ & $\begin{array}{r}-.061 \\
(.236)\end{array}$ & $\begin{array}{c}-.295 \\
(.302)\end{array}$ & $\begin{array}{c}.030 \\
(.343)\end{array}$ \\
\hline Father farmer & & & $\begin{array}{c}-.159 \\
(.162)\end{array}$ & $\begin{array}{c}-.183 \\
(.169)\end{array}$ & $\begin{array}{l}.064 \\
(.252)\end{array}$ & $\begin{array}{c}-.326 \\
(.211)\end{array}$ \\
\hline Father's schooling & & & $\begin{array}{l}.038 \\
(.021)\end{array}$ & $\begin{array}{l}.028 \\
(.021)\end{array}$ & $\begin{array}{c}.034 \\
(.027)\end{array}$ & $\begin{array}{r}-.007 \\
(.036)\end{array}$ \\
\hline Mother's schooling & & & $\begin{array}{l}.130 \\
(.041)^{* * *}\end{array}$ & $\begin{array}{l}.108 \\
(.042) *\end{array}$ & $\begin{array}{l}.118 \\
(.047)^{*}\end{array}$ & $\begin{array}{l}.058 \\
(.092)\end{array}$ \\
\hline Hindu & & & $\begin{array}{l}.936 \\
(.215) * *\end{array}$ & $\begin{array}{l}.776 \\
(.270) * *\end{array}$ & $\begin{array}{l}1.313 \\
(.361) * *\end{array}$ & $\begin{array}{l}.777 \\
(.266) * *\end{array}$ \\
\hline Mom alive age 50 & & & $\begin{array}{l}.219 \\
(.217)\end{array}$ & $\begin{array}{l}.210 \\
(.216)\end{array}$ & $\begin{array}{l}.564 \\
(.315)\end{array}$ & $\begin{array}{c}-.064 \\
(.300)\end{array}$ \\
\hline Dad alive age 50 & & & $\begin{array}{c}-.190 \\
(.237)\end{array}$ & $\begin{array}{c}-.231 \\
(.247)\end{array}$ & $\begin{array}{c}-.452 \\
(.318)\end{array}$ & $\begin{array}{c}-.033 \\
(.330)\end{array}$ \\
\hline Village fixed effects & No & No & No & Yes & No & No \\
\hline Universe & All & All & All & All & $\begin{array}{l}\text { In school } \\
\text { at age } 9\end{array}$ & $\begin{array}{c}\text { Out of } \\
\text { school at } \\
\text { age } 9\end{array}$ \\
\hline$F$-statistic & 140.11 & 34.18 & 145.97 & 152.01 & 61.75 & 81.09 \\
\hline Observations & 2,101 & 2,101 & 2,101 & 2,101 & 1,012 & 1,089 \\
\hline
\end{tabular}




\section{Estimation Issues}

\section{A. Endogenous Instruments}

In order to identify an IV model using age of menarche as an instrument for marriage timing, the exclusion restriction requires that the relationship between puberty and adult outcomes is fully mediated by changes in age at first marriage, such that delayed marriage is the only pathway through which physical maturation influences schooling. Biological research into the determinants of age of menarche reveals that genetic factors are by far the strongest predictors of adolescent development and that random genetic variation is a significant component of timing (Campbell and Udry 1995). For instance, in one landmark study, Kaprio et al. (1995) compared the correlation in age of onset across 1,283 pairs of monozygotic and dizygotic twins and found that the correlation in age of onset among dizygotic twins was merely 0.21 , whereas the correlation among monozygotic twins was nearly three times as large. These differences indicate a high degree of genetic determinism and hence a minimal role of environmental influences on maturation. ${ }^{11}$

While these patterns indicate a high degree of variation in timing of menarche that is unrelated to family background, there is nevertheless room for external influences on age of onset that may be particularly relevant in less developed countries. The following factors are known from laboratory experiments to have the potential to influence menarche: geography and climate (altitude and cold weather are thought to delay puberty; Nazian and Piacsek 1976; Lehrer 1986); strenuous physical activity or stress (ambiguous direction of influence, but in most cases causes delay; Bronson 1987; Pellerin-Massicotte et al. 1987); exposure to endocrine-disrupting chemicals, including hormone-mimicking agents or other toxic substances such as lead (direction of influence varies by compound: estrogen-mimicking compounds hasten onset whereas testosterone-mimicking compounds delay onset) $;^{12}$ sex composition of peer group (ambiguous direction; Vandenbergh 1969; Vandenbergh, Whitsett, and Lombardi 1975; Mucignat-Caretta, Caretta, and

\footnotetext{
${ }^{11}$ The same study estimated that genetic factors explained 74 percent of variance in age at menarche, a finding that is consistent with many other estimates of heritability from human (Gedda and Brenci 1975; Fishbein 1977; Sklad 1977; Meyer et al. 1991) and animal studies (Nelson et al. 1990).

${ }^{12}$ See Der et al. 1974; McLachlan and Dixon 1977; Gellert 1978; Kimmel et al. 1980; Kramer and Meijs-Roelofs 1982; Yamada, Itoh, and Ohta 1989; Walters, Rourke, and Eroschenko 1993; Whitten 1993; Gellert 1995; Gray and Ostby 1995; Toppari, Larsen, and Christiansen 1996; Cooper and Kavlock 1997; Howdeshell and vom Saal 1997; Komura et al. 1998; Andersson and Skakkebaek 1999; Monosson et al. 1999; Clark, Kelton, and Whitney 2000; Laws et al. 2000; Stoker et al. 2000; Whitney and Clark 2001; Withuhn, Kramer, and Cushing 2003; and Golub et al. 2004.
} 
Cavaggioni 1995); and abrupt changes in diet resulting in acute malnutrition in utero or in childhood (delays onset). ${ }^{13}$

The first five factors are unlikely to confound our analysis. In the relatively small and uniformly rural district of Matlab, there is little variation in climate or altitude. Sex composition of peer groups is arguably distributed across individuals independently of adult outcomes. While exposure to environmental pollutants such as lead and pesticides is strongly correlated with income in some settings, within Matlab, chemical exposure is unlikely to confound the analysis when age is controlled for. Similarly, while in many parts of the world hard labor is strongly associated with poverty, it is unlikely to vary within this population since very few adolescent girls engage in work outside of the residence.

In contrast, the potential correlation between menarche and nutrition is a concern in this sample: the rate of acute malnutrition in rural Bangladesh was 10.7 percent in 1999 (World Health Organization Global Database on Child Growth and Malnutrition 1999; see also Shahabuddin et al. 2000). The extent to which this poses a problem for our analysis depends on whether differences in nutrition are large enough to exert an influence on endocrine systems. Though a vast number of nonexperimental studies suggest that age of menarche is potentially sensitive to moderate changes in nutritional intake, results from human studies are inconclusive because of the difficulty of isolating influences on puberty in nonexperimental settings. A review of this literature and its shortcomings is detailed in Field (2007). As a result, laboratory experiments arguably provide the only reliable evidence on sources of interference.

While experiments show that food restriction has the potential to trigger delays in onset of puberty, this body of research reveals two important caveats. First, there is ample evidence that the influence of nutrition on hormone-releasing agents that trigger menses is experienced only at extremely high levels of food restriction. Among the laboratory studies investigating the correlation between food restriction and pubertal development reviewed as part of the Environmental Protection Agency's Endocrine Disrupter Screening Program (EDSP), only differences in food intake that reduced weight gain by more than 50 percent during developmental stages preceded and followed by an abrupt return to normal levels of food intake resulted in delayed onset

\footnotetext{
${ }^{13}$ All laboratory evidence involves abrupt changes in food intake as opposed to chronic deprivation, so it is ambiguous whether such a shock is necessary to throw the hormone system off balance.
} 
of puberty. ${ }^{14}$ More important, there is also significant evidence that any change in nutrition that has consequences for the timing of menarche would reveal itself in growth stunting. While no studies contained in the EDSP review in which food intake was manipulated to reduce body weight gain by 10-34 percent had any effect on menarche, stunting occurred at considerably lower levels of food restriction. Extensive animal studies from the 1910s and 1920s (see Krogman 1972, 135-37) also show consistently that malnutrition has a far bigger effect on growth in size than on maturational progress. Hence, while it is difficult to extrapolate observed dose responses to human populations, even a conservative interpretation of laboratory results indicates that only malnutrition severe enough to cause stunting during childhood could cause a delay in menarche, consistent with a recent assessment of human populations (Stathopolu, Hulse, and Canning 2003). This fact allows us to assess the degree of endogeneity with data on the height of women in our sample. Adult height is commonly linked to early health status and nutrition. Since height is largely driven by prepubescent growth, it is widely considered to capture the degree of stunting due to inadequate nutrition and health in childhood. ${ }^{15}$

Table 1 presents summary statistics broken down by menarche age terciles for a number of adult outcomes available in the MHSS, including height. If the claim is correct that undernutrition severe enough to delay menarche will necessarily reveal itself in extreme stunting, the data indicate no significant association between nutrition and age of menarche in the population of girls who reach puberty in the restricted age range. In a regression of adult height on age of menarche, the coefficient estimate is very close to zero and insignificant, evident in the height data in row 2 (cols. 4-6) of table 1. Figure 3 shows the kernel density estimate of adult height by terciles of menarcheal age, revealing that the population distributions and not just averages are remarkably similar across all subsamples. ${ }^{16}$ This evidence is also consistent with the

\footnotetext{
${ }^{14}$ See Kennedy 1957; Widdowson and McCance 1960; Kennedy and Mitra 1963; Ronnekleiv, Ojeda, and McCann 1978; Merry and Holehan 1979; Wilen, Bastomsky, and Naftolin 1981; Aguilar et al. 1984; Friedman et al. 1990; I'Anson et al. 1991; Wade and Schneider 1992; Ahima et al. 1996, 1997; Barash et al. 1996; Chehab et al. 1997; Cheung et al. 1997, 2001; Plant and Durant 1997; Schneider, Hall, and Wade 1997; Dougherty et al. 1998; Vasallo et al. 1998; Howenstein et al. 2000; Messer and I'Anson 2000; Engelbregt et al. 2002; and Mann and Plant 2002. A summary table is available at http://www.epa .gov/scipoly/oscpendo/pubs/edmvs/foodstudyreftable.pdf.

${ }^{15} \mathrm{~A}$ number of studies suggest that the height of a child by age 4 is a discriminating indicator of previous nutrition and childhood disease and a reasonably accurate predictor of adult height (Martorell and Habicht 1986; Fogel 1990, 1991; Martorell 1993; Herrinton and Husson 2001).

${ }^{16}$ If anything, adult height appears to be slightly skewed to the left for girls who mature early, consistent with studies from development biology that show that reaching puberty early is associated with a shorter stature in adulthood with no corresponding effects on health.
} 


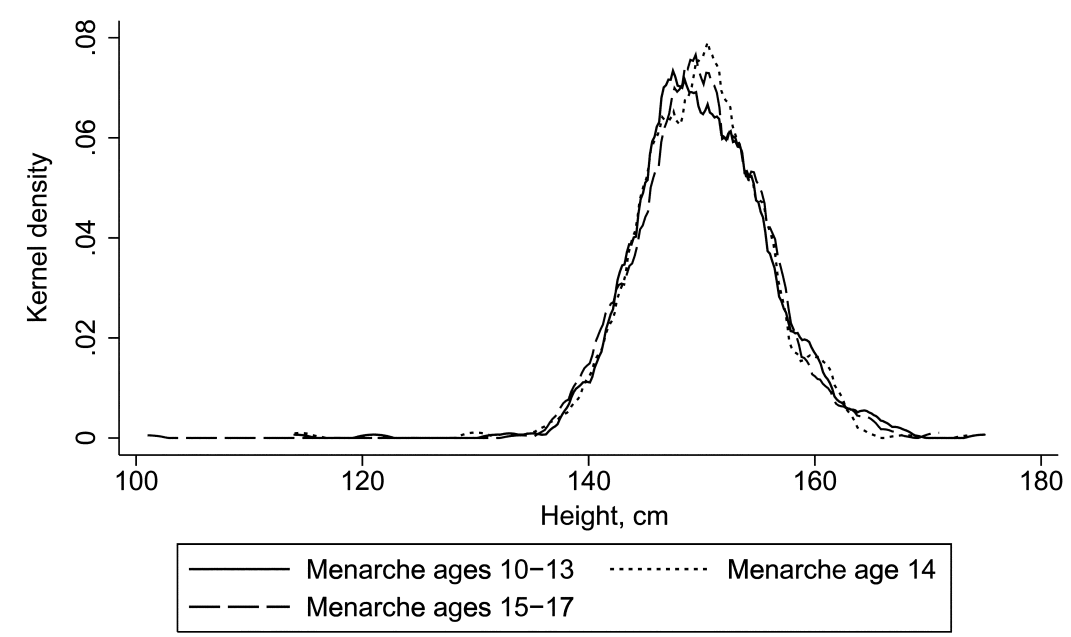

FIG. 3.-Adult height. Data are taken from the 1996 MHSS. The sample includes evermarried women between 25 and 45 with nonmissing values for age at marriage and age at menarche who reached menarche between 11 and 17. Epanechnikov kernel, bandwidth $=0.8$.

results of a recent detailed health study conducted in four rural villages of Bangladesh, which found no statistically significant differences in the prevalence of major health conditions among menstruating and nonmenstruating girls below age 16 (Chowdhury et al. 2000). Other family background characteristics reinforce the anthropometric evidence. None of the following measures appear to differ significantly by age of menarche: father's and mother's education, family wealth, and number of siblings (table 1). ${ }^{17}$ Furthermore, there is no significant association between age of menarche and a range of indicators of adult health status (table 1).

This set of evidence suggests that much of the variation in timing of first menstruation is uncorrelated with determinants of adult well-being other than marriage age and that differences in family background according to age of menarche are unlikely to confound the analysis. Height can also be included as a right-hand-side variable in the regression analysis in order to control for early nutritional status. Because adult height may not be a sufficient statistic for childhood nutrition, we

${ }^{17}$ Nor is there an apparent difference in menarcheal age, with height controlled for, by time trends in economic conditions. Statistical tests confirm the absence of a significant correlation between puberty and national GDP or average rainfall (gathered from the University of Delaware Air and Temperature Precipitation Data for years 1950-96) during childhood. Estimates are available from the authors on request. 
also control for other available indicators of childhood socioeconomic status (SES), listed in Section III.C.

Perhaps most important, the potential association between age at menarche and early childhood nutritional status is substantially less of a concern because low SES is universally associated with lower educational attainment. Hence, omitted variables related to childhood SES in equation (2) would presumably bias downward our IV estimates of the causal effect of delayed marriage on education and literacy (by biasing downward our first-stage estimates of the effect of menarche on marriage). In addition, because endogeneity is an issue of central concern to the analytical methods, we limit the age range of menarche to 11-16 years in order to reduce the likelihood that maturation is correlated with family background. This range covers 90 percent of women in the sample. Both very early and very late first menstruation are linked to chronic medical conditions, as well as extreme physical and emotional stress (Palmert and Boepple 2001).

\section{B. Selective Mortality}

Another estimation issue in using retrospective information is selective mortality. If either early marriage or early menarche is associated with higher mortality in adulthood, the estimates could be biased. For this reason, we restrict the sample to women under the age of 44. Data from the region indicate that selective mortality is unlikely to present a problem within this range: According to MHSS data on respondents' mothers, 82 percent of mothers born between 1935 and 1945 are alive in 1996. Although the statistic is not perfectly analogous to the probability of dying between 15 and 43 since mothers are on average older than 15 , life expectancy should be significantly higher for women in younger cohorts and at younger ages. ${ }^{18}$

\footnotetext{
${ }^{18}$ In addition, we restrict the sample to women between the ages of 26 and 44 since women over 43 in 1996 were unlikely to have any opportunity to attend secondary school. Owing to extremely limited educational opportunities for girls in rural Bengal prior to 1962, less than a third of MHSS women over 43 were enrolled in school at age 9, and only 3.64 percent attended secondary school, implying that very few women remained in school long enough for matriculation to be affected by physical maturation. According to MHSS data, 75 percent of schools in the region were established after 1960. In 1960, there were only four secondary schools in Matlab, only one of which accepted girls. We choose the cutoff age for schooling opportunities to be consistent with the cutoff age in the regression analysis: when the first schools built during expansion opened in 1962, women born in 1953 would have been 9 years old, so we identify this cohort as the first group of women for whom secondary school was a real possibility.
} 


\section{Recall Bias}

Another concern with the data is potential measurement error due to recall bias or systematic misreporting in the variables collected retrospectively. As mentioned earlier, the ability to double-check birth and marriage data with DSS records eliminates much of the concern over measurement error in these data. ${ }^{19}$ In contrast, it is not possible to crosscheck age of menarche with outside sources since no records are kept of this event by government or health practitioners. Given this, one fear is that imperfect recall may lead respondents to approximate menarche with marriage such that the correlation is spuriously strengthened.

We do not expect measurement error to present a significant problem in these data for two reasons. First, recalled age of menarche has been shown to be highly reliable in numerous studies. According to a survey by Ellis $(2004,921)$, "both adolescent girls and adult women are generally willing and able to report accurately on their ages at menarche . . . and retrospective reports may be more reliable than those obtained during puberty" (reviewed in Graber, Brooks-Gunn, and Petersen [1996]; see also Dorn et al. 1999). ${ }^{20}$ Although women in Matlab are in many ways uncharacteristic of average respondents, special care was taken by MHSS survey takers to collect accurate reproductive histories, including probing respondents with memory triggers and monitoring responses with a range of consistency checks (Rahman et al. 1999). Furthermore, since the DSS has operated for over 30 years in Matlab, residents are relatively accustomed to calculating and reporting ages associated with life cycle events. Hence, it is reasonable to expect respondents to report menarche with equal accuracy.

Second, owing to the social importance of this event in rural society, marked by many important and dramatic lifestyle changes, it is reasonable to expect that women remember the timing with even greater precision than women in developed countries. For example, as soon as a Muslim girl in Bangladesh reaches menstruation, she is instructed to pray five times a day, to keep fast, to wear special clothes such as long shirts and trousers, and to cover her head and breast with a veil (Begum 2003). According to a recent qualitative study of adolescents in Matlab, 100 percent of girls associate menarche with changes in dress, and 67 percent associate menarche with increased housework (Bosch 2001,

\footnotetext{
${ }^{19}$ Because a considerable fraction of women either were born outside of Matlab or are too old to have complete demographic records, we conduct separate analyses of older cohorts and in-migrants.

${ }^{20}$ As the article elaborates, "Test-retest reliability has been established in several longterm prospective studies in which self-reported age at menarche was first obtained in adolescence and then again 17 to 37 years later. Correlations across these two measurement periods have been consistently high, ranging from .67 to .79" (Livson and McNeill 1962; Damon et al. 1969; Casey et al. 1991; Must et al. 2002).
} 
chap. 7). Additional research reports that the majority of girls are unaware of menstruation before it begins and as a result frequently are terrified and traumatized by the event (Nahar et al. 1999). The religious beliefs associated with these practices in addition to observable physical changes that occur with puberty also decrease the possibility that families are willing and able to disguise menarche in an effort to reduce potential stigma associated with postponing wedlock. Furthermore, there is no anecdotal evidence that the stigma of marrying late falls as puberty rises. If anything, families have strong economic incentive to reveal a daughter's eligibility for marriage as soon as it is socially acceptable to do so.

Finally, there is no empirical evidence of significant recall bias. For instance, many types of imperfect recall would show up in changes in the distribution of menarcheal age over time, yet the data reveal no significant heteroskedasticity with respect to menarche reports and respondents' age. ${ }^{21}$ A more comprehensive diagnostic check involves comparing the distributions of menarche age between women with educated and uneducated mothers, reported in figure 4 . In particular, we separate mothers according to whether they were sent to school before age 10 , which is presumably unrelated to maturation. Here, the idea is to isolate a group of families who have a preexisting preference for later marriage unrelated to their daughter's maturation. Since menarche is exogenous to this preference, a significant difference in reported age of onset across these types would suggest either recall bias or strategic misreporting. Instead, as revealed in figure $4 A$, while the first group has a significantly higher first marriage age and the distribution of marriage age is strongly shifted to the right, figure $4 B$ reveals no significant difference between the distributions of age of onset across the subsamples.

\section{Intergenerational Effects}

The genetic component of age of menarche may imply that women with later onset have the additional advantage of having mothers who also experienced later marriage. In this sense, the benefits of later marriage may be transmitted through intergenerational linkages other than biology. If late marriage leads to higher schooling attainment, families in which this biological trait is prevalent across generations may be those with persistently higher investment in girls.

While the data will not allow us to directly measure intergenerational correlations between age of menarche and marriage timing, we predict the influence of this indirect channel to be relatively minor for a number

\footnotetext{
${ }^{21}$ Potential population changes over time in age of menarche limit the ability to perform standard diagnostic checks of additive measurement error with age. For instance, it is ambiguous whether the fact that average age of menarche rises slightly over time reflects a biological phenomenon or a relationship between recall bias and age.
} 


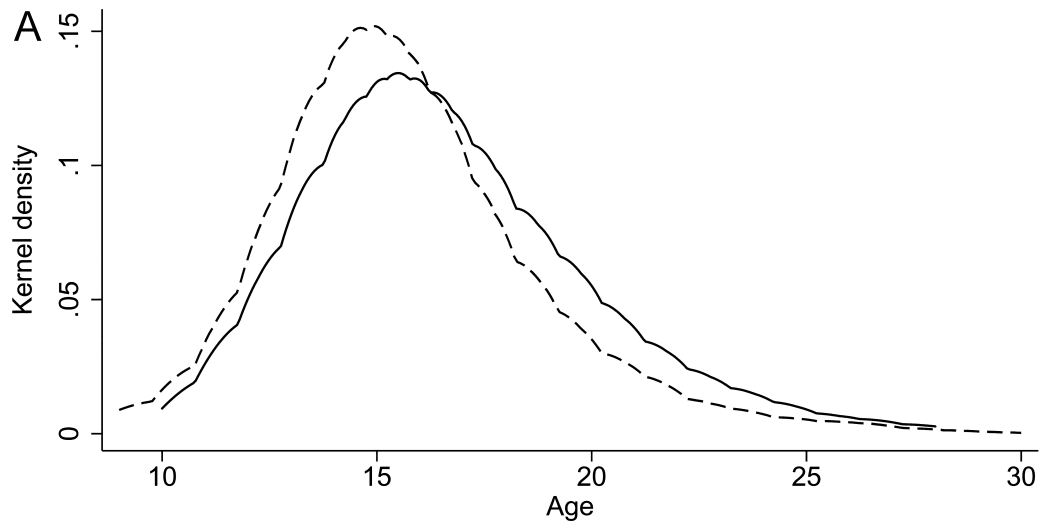

Mother unschooled --- - Mother unschooled

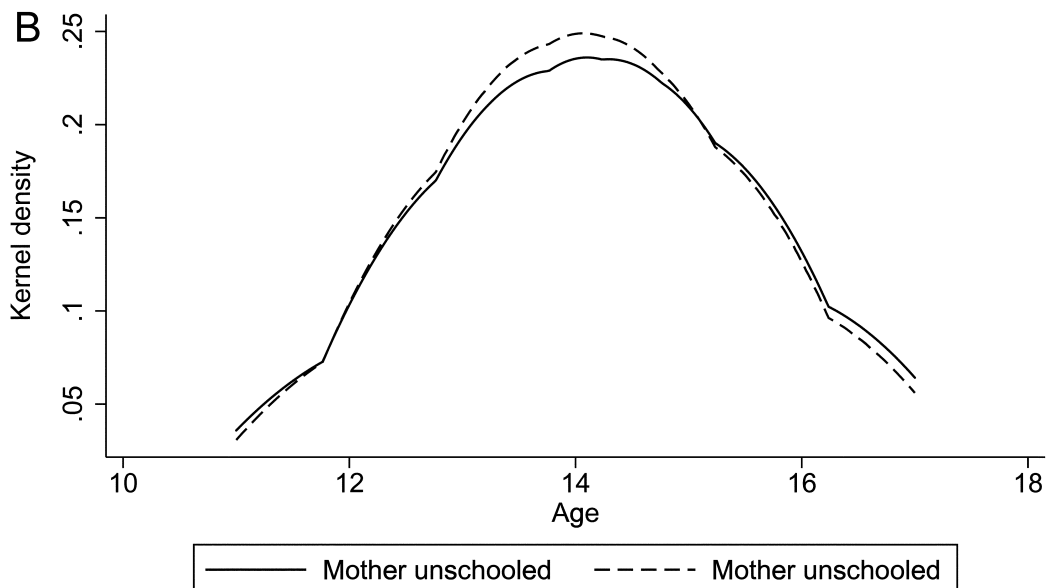

Fig. 4.-A, Age of marriage, schooled and unschooled mothers. B, Age of menarche, schooled and unschooled mothers. Data are taken from the 1996 MHSS. The sample includes ever-married women between 25 and 45 with nonmissing values for age at marriage and age at menarche who reached menarche between 11 and 17. Epanechnikov kernel, bandwidth $=1$.

of reasons. ${ }^{22}$ First, marriage timing has little potential influence on the schooling outcomes of older cohorts of women, for whom schooling opportunities were extremely scarce. Second, means in table 1 reveal that observable measures of family background are balanced by menar-

${ }^{22}$ An unfortunate disadvantage of these data is that the sample of ever-married women contains very few sibling or mother-daughter pairs because in rural areas of the country, married couples generally live in the husband's parents' household during the husband's father's lifetime. 
che age group. Finally, regression controls for available family background characteristics minimize the potential influence of second-order effects on the empirical estimates.

\section{Results}

\section{A. Schooling and Literacy}

To gauge the impact of marriage timing on schooling attainment, we measure the impact of delayed marriage on highest grade attained and literacy rates among women who were enrolled in school at age $9 .{ }^{23} \mathrm{We}$ restrict the sample to those who were enrolled in school at age 9 in order to focus the analysis on girls for whom the marriage constraint is potentially binding. This amounts to isolating the treatment on the treated as opposed to calculating the intent-to-treat effect, which provides valuable precision when close to half of the population is known to be outside the sphere of influence. Although earliest menarche is 11 , we choose 9 as the cutoff point for school attendance since signs of menarche may appear up to 2 years before onset.

Results from the IV estimates for schooling and literacy are reported in table 3 alongside corresponding OLS estimates. Columns 1-4 report grade attainment and literacy for women who were enrolled at 9 . The results indicate that postponing marriage by 1 year between ages 11 and 16 increases educational attainment by an average of 0.22 year. Correspondingly, an additional year of delay increases adult literacy by 5.6 percent (4.1 percentage points). These estimates suggest that universal marriage postponement would generate substantial increases in educational attainment and literacy among those who have access to primary school, ceteris paribus. For instance, expanding this estimate by the number of postponed marriage years necessary to increase the average marriage age from 15 to the legal minimum of 18 implies a 14.2 percent increase in average female schooling and an almost identical change in female literacy. Columns 5-8 repeat this exercise for the full sample of women, including the roughly 50 percent who were never enrolled in school and 6 percent who either started school after 9 or dropped out of school before 9. Not surprisingly, the intend-to-treat estimates of marriage age on schooling among the full sample are much weaker in both the OLS and IV specifications. Just as we would expect, the estimated magnitude is roughly half the size when all girls are included, and the attainment results are significant only at the 10 percent level.

Columns 9 and 10 of table 3 show results from a control experiment

\footnotetext{
${ }^{23}$ Literacy is defined broadly from respondents' reports of reading and writing ability on a scale of 1-3. Respondents who reported either 1 or 2 on both measures were considered literate.
} 


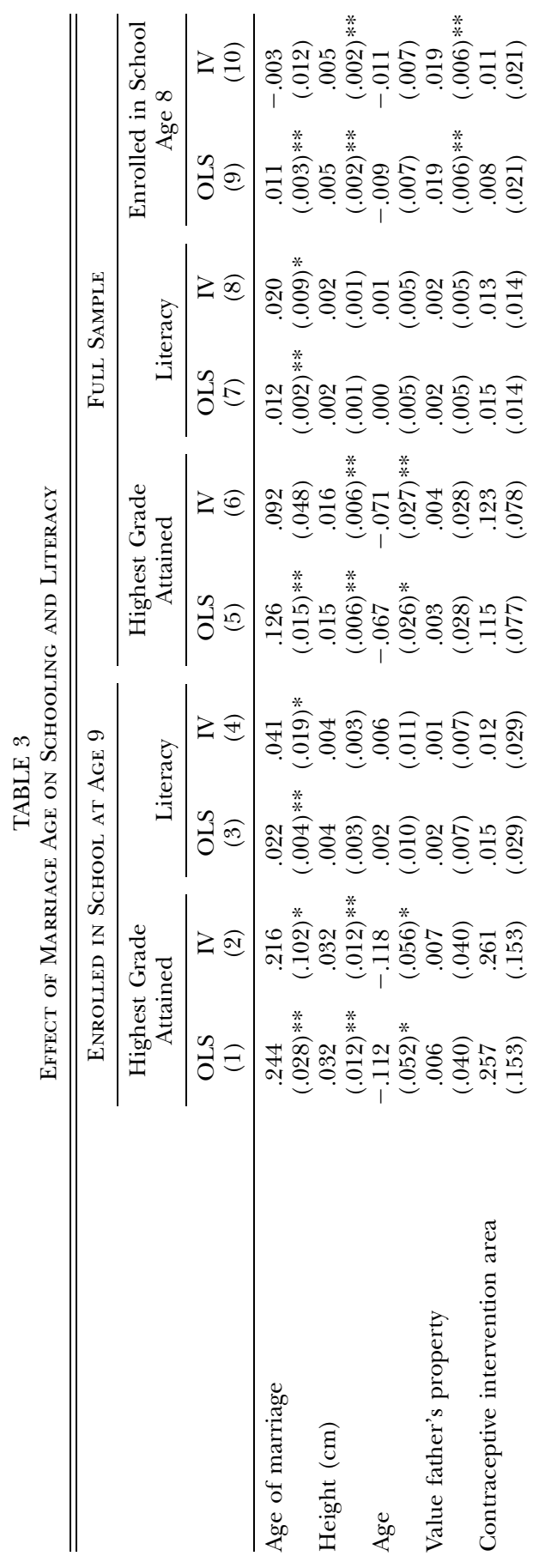




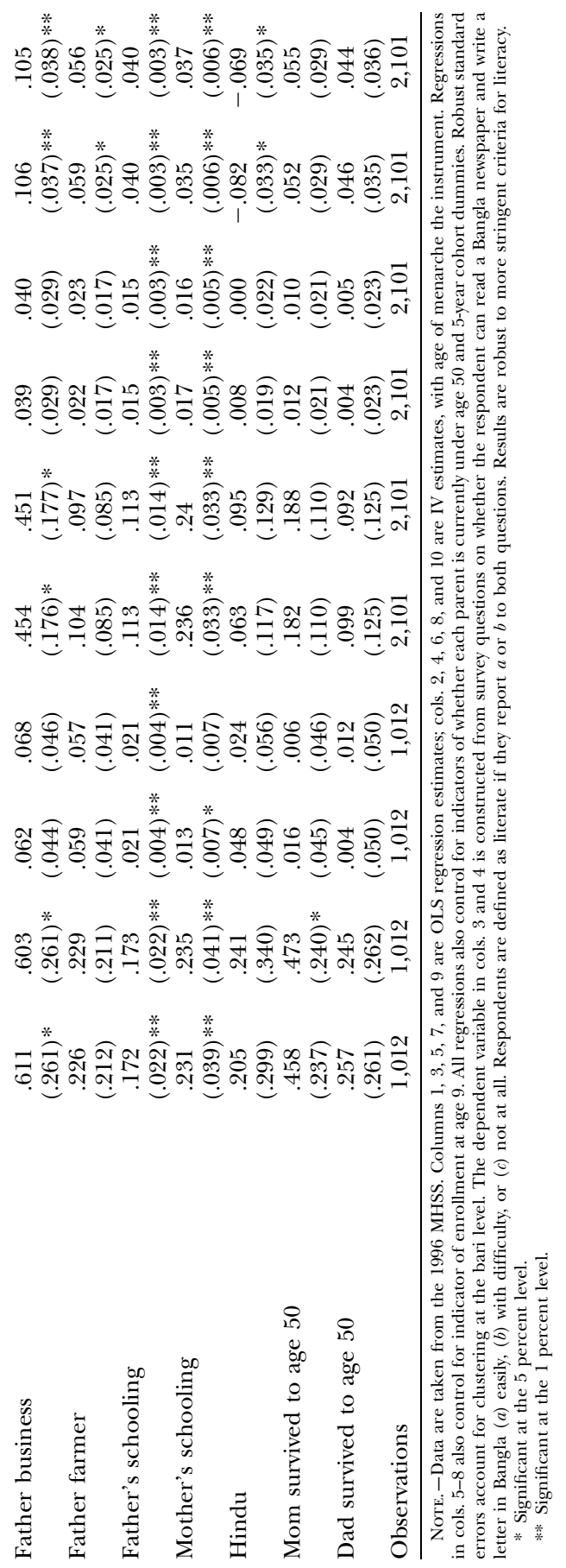


in which marriage age instrumented with menarcheal age is regressed on school enrollment at 8. Assuming that parents cannot predict timing of puberty from girls' observable characteristics at 8 , the positive and significant coefficient on marriage age in column 9 indicates the presence of unobservable determinants of both schooling and marriage age that bias OLS estimates upward. Meanwhile, the IV estimate is close to zero and insignificant, suggesting that the instrument is not contaminated by the same unobservable correlates.

\section{B. Direct Effect of Menarche on Schooling}

Menarche itself may be the barrier to schooling, in which case increasing legal age at marriage would not have the estimated effect on education. This violation of the IV exclusion restriction could arise if traditional rules governing female mobility prevented girls from attending school after first menstruation. As opposed to the case of marriage, the MHSS data reveal that puberty is not a universal constraint on school attendance: 75 percent of girls who are enrolled in school a year before menarche remain in school for at least 2 years, and their average length of time in school after menarche is 2.5 years. Still, it could be the case that all of the estimated schooling effect is attributable to a relaxation of the puberty constraint facing up to 25 percent of girls from traditional families.

To test whether menarche has a direct effect on schooling, we examine variation in the magnitude of estimates across women facing different observable constraints on marriage timing based on sex-specific birth order, a characteristic that is exogenous to age of puberty. Because of the traditional preference for marrying daughters according to birth order, women with older female siblings should have less opportunity to respond to early maturation since they face additional constraints imposed by sibling marital status. Hence, if education is influenced by marriage opportunities rather than by puberty itself, schooling responses to puberty should be larger on average among first-born girls and decline steadily with sex-specific birth order. In contrast, if the effect of puberty delay is driven solely by traditional attitudes toward school attendance, the effects should be independent of birth order. To test this, we restrict the sample to women with at least one female sibling (90 percent of the sample) and regress schooling attainment on age of menarche and age of menarche interacted with the number of older female siblings and sex-specific birth order. ${ }^{24}$ Because the number of

\footnotetext{
${ }^{24}$ Sex-specific birth order is defined as the number of older female siblings divided by the total number of female siblings.
} 
TABLE 4

Influence of Menarche on Schooling According to SeX-Specific Birth Order and Observation of Religious Customs

\begin{tabular}{|c|c|c|c|c|c|}
\hline & \multirow{2}{*}{$\begin{array}{l}\text { AGE OF } \\
\text { MARRIAGE } \\
(1)\end{array}$} & \multirow{2}{*}{$\begin{array}{l}\text { Age Quit } \\
\text { SchOOL } \\
(2)\end{array}$} & \multirow{2}{*}{$\begin{array}{c}\text { HigheST } \\
\text { GRADE } \\
\text { ATTENDED } \\
(3)\end{array}$} & \multicolumn{2}{|c|}{ AgE Quit SchoOL } \\
\hline & & & & (4) & (5) \\
\hline Age of menarche & $\begin{array}{l}.397 \\
(.114) * *\end{array}$ & $\begin{array}{l}.934 \\
(.124) * *\end{array}$ & $\begin{array}{c}.241 \\
(.108)^{*}\end{array}$ & $\begin{array}{l}.172 \\
(.079) *\end{array}$ & $\begin{array}{l}.259 \\
(.139) * * *\end{array}$ \\
\hline $\begin{array}{l}\text { Sex-specific birth } \\
\text { order }\end{array}$ & $\begin{array}{c}4.698 \\
(2.411)\end{array}$ & $\begin{array}{c}6.609 \\
(2.982) *\end{array}$ & $\begin{array}{c}4.157 \\
(2.355)\end{array}$ & & \\
\hline $\begin{array}{l}\text { Sex-specific birth } \\
\text { order } \times \text { Age of } \\
\text { menarche }\end{array}$ & $\begin{array}{l}-.329 \\
(.163)^{*}\end{array}$ & $\begin{array}{l}-.387 \\
(.201)\end{array}$ & $\begin{array}{l}-.303 \\
(.160)^{*}\end{array}$ & & \\
\hline $\begin{array}{l}\text { Number of female } \\
\text { siblings }\end{array}$ & $\begin{array}{c}-.111 \\
(.095)\end{array}$ & $\begin{array}{c}-.036 \\
(.108)\end{array}$ & $\begin{array}{c}-.08 \\
(.093)\end{array}$ & & \\
\hline Number of siblings & $\begin{array}{l}.058 \\
(.054)\end{array}$ & $\begin{array}{l}.015 \\
(.063)\end{array}$ & $\begin{array}{l}.05 \\
(.058)\end{array}$ & & \\
\hline Universe & $\begin{array}{l}\geq 1 \text { female } \\
\text { sibling }\end{array}$ & $\begin{array}{l}\geq \underset{\text { female }}{1 \text { fibling }} \\
\text { to }\end{array}$ & $\begin{array}{l}\geq 1 \text { female } \\
\text { sibling }\end{array}$ & $\begin{array}{l}\text { Always wear } \\
\text { head scarf } \\
\text { in presence } \\
\text { of men }\end{array}$ & $\begin{array}{l}\text { Do not always } \\
\text { wear head } \\
\text { scarf in } \\
\text { presence } \\
\text { of men }\end{array}$ \\
\hline Observations & 851 & 851 & 851 & 847 & 304 \\
\hline
\end{tabular}

NotE. - Data are taken from the 1996 MHSS. Regressions in cols. 1-3 are restricted to girls with at least one female sibling. All regressions are restricted to the subsample of girls who are in school at age 9 . To standardize for family size, sex-specific birth order is measured as the number of older female siblings divided by the total number of female siblings. All estimates are robust to including year of birth or 5-year cohort dummies. A woman is classified as always wearing a head scarf in the presence of men if she answered "always" to both of the following survey questions: "Do you cover your head inside the bari in the presence of men?" and "Do you cover your head inside the bari in the presence of outsider men?"

* Significant at the 5 percent level.

** Significant at the 1 percent level.

*** Significant at the 10 percent level.

female siblings may be correlated with other family characteristics, all regressions control for total female and male siblings.

Results from both specifications are presented in table 4 . The estimates indicate that the schooling attainment of younger daughters is significantly less sensitive to age of menarche than that of older daughters. Since elder and younger daughters are evenly distributed across traditional and nontraditional families conditional on sibship size, this indicates within-family differences in the effect of menarche on schooling, which must therefore be independent of parents' preference to keep girls out of school when they reach puberty. A coarser way of studying these relationships is to run the baseline regressions separately for eldest and younger daughters. Doing so reveals that, conditional on enrollment at 10 , the age of quitting school is sensitive to menarche only for eldest daughters. Unless traditional attitudes systematically apply only to eldest girls, this finding provides strong evidence that puberty 
does not directly cause girls to quit school. It is hard to imagine that any social norm grounded in religious beliefs would vary systematically according to birth order.

As a second check on whether our results are driven by a direct influence of menarche on school attendance, we divide the sample according to religious practices associated with reaching puberty. In particular, the vast majority of women in our sample ( 74 percent of the analysis sample) report currently wearing a head scarf in the presence of men from both inside and outside the bari, a change in dress that is traditionally required beginning at the onset of puberty. By regressing dropout age on age of menarche separately in these two subsamples, we test whether the relationship between schooling and menarche is as strong among women who do not observe such practices. Indeed, a comparison between the estimated coefficient on age of menarche in columns 4 and 5 of table 4 reveals that schooling attainment and onset of puberty are just as highly correlated among women who are substantially less observant of traditional gender norms. The estimated effect of menarche on schooling is virtually unchanged when the sample is restricted to the minority of women least likely to observe restrictions on dress and mobility associated with puberty.

Both findings are consistent with two additional pieces of evidence: First, in a recent qualitative study of adolescents' views about menarche in Matlab, 86 postmenarcheal adolescent girls were asked to list all lifestyle changes associated with menarche (Bosch 2001, chap. 7). Although a wide range and number of changes were reported, school attendance was not mentioned. In contrast, 67 percent report that they started helping with daily chores. Second, MHSS respondents were asked the primary reason they quit school, and none cite puberty or menarche.

\section{Secondary Outcomes}

\section{Health Care Behavior}

Both an increase in education and an increase in marriage age may have secondary effects on female outcomes. To explore this, we analyze MHSS data on health care practices during pregnancy, including the rate at which a woman seeks prenatal care when she is pregnant, the average number of prenatal visits, and whether she has ever received an antitetanus shot while pregnant. ${ }^{25}$ Although there is evidence from

\footnotetext{
${ }^{25}$ Variables were constructed from averaging responses across all pregnancies from the following survey questions asked about each of a woman's pregnancies: (1) "During pregnancy . . . did you ever have a pregnancy check-up?" (2) "How many antenatal visits did you have during . . . pregnancy?" (3) "When you were pregnant with . . . were you given an injection in the arm to prevent the baby from getting tetanus, that is, convulsions after birth?"
} 
past research that many health behaviors are positively influenced by schooling, the effect of early marriage on preventive care may operate through channels other than education. In particular, girls who begin their reproductive cycle at younger ages may be more isolated or less empowered and as a result less likely to seek appropriate health care during pregnancy and childbirth. To make this conceptual distinction clear, we refer to behavioral changes related to marriage age but not education as "age effects."

To empirically disentangle the effects of education from determinants of health care practices related to marriage age, we make use of the fact that the education effects of marriage timing are experienced only by the subpopulation of girls who were enrolled in primary school. In this manner, marriage age and schooling attainment can be separately identified by comparing subsamples of women who were and were not enrolled in school at age 9. Only if the influence of marriage age is restricted to the former group could education gains be entirely responsible for behavior change. If the unschooled are also better off, age effects must play a role. Table 5 presents results from the IV analysis on both subsamples. In all estimates, age of marriage is instrumented by age of menarche as in the previous regressions.

These estimates suggest that health care practices improve substantially with later marriage. Interestingly, the estimates reveal significant improvements in prenatal care not only among the educated but also among the subpopulation for whom schooling is unaffected by marriage age, indicating that the increases in health care utilization do not operate exclusively through changes in schooling. A year of marriage delay is associated with an 8.6 percent increase in the likelihood of prenatal care during pregnancy for women who attended school and a 9.1 percent increase for woman who did not attend school. There is also an associated increase on the intensive margin: a year of marriage delay is associated with a 5.7 percent increase in the average number of antenatal visits for women who attended school and an 11.6 percent increase for woman who did not attend school, and the effect is significant only for the latter. There is also a strong estimated influence of marriage age on receiving antitetanus shots during pregnancy among girls who did (11 percent) and did not (8.5 percent) attend primary school.

The results indicate that, whereas educated women are encouraged to take up prenatal services as a result of marrying late, uneducated women are influenced by later marriage only in terms of switching from one to several clinic visits. One interpretation of this pattern is that secondary school improves women's awareness of available health services, thereby increasing the likelihood that they will seek out any care. Meanwhile, marriage age alone increases the likelihood that a woman will have the freedom to take advantage of services known to her, for 


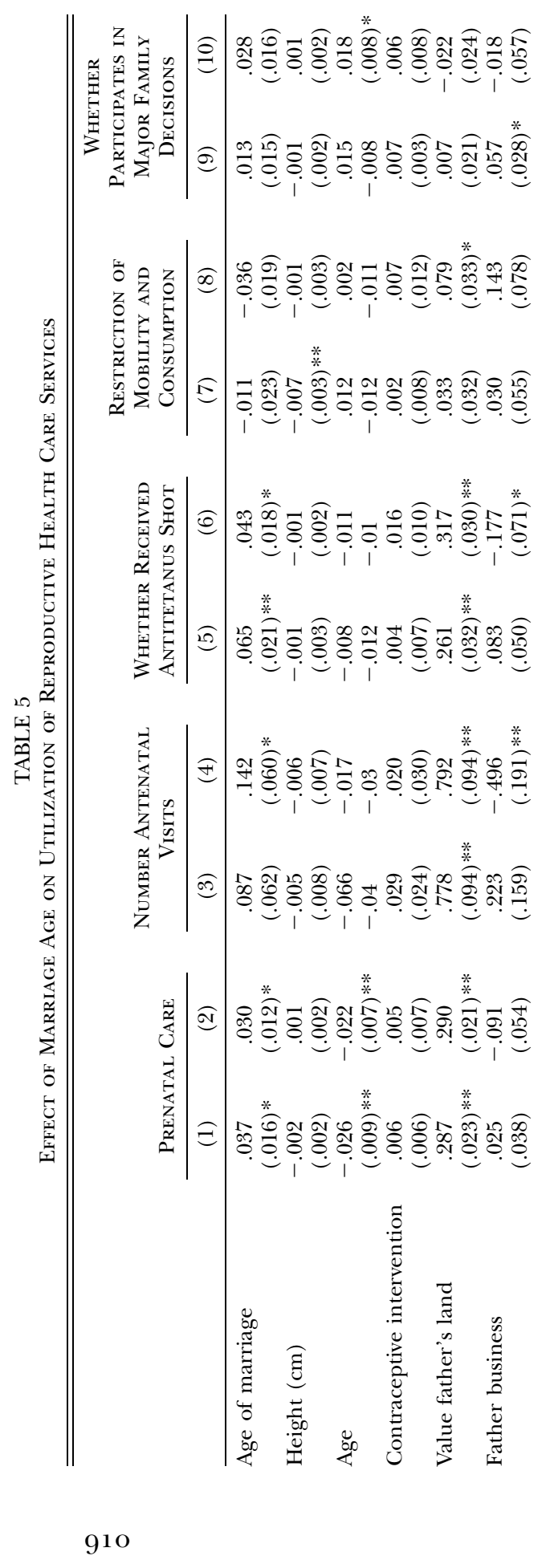




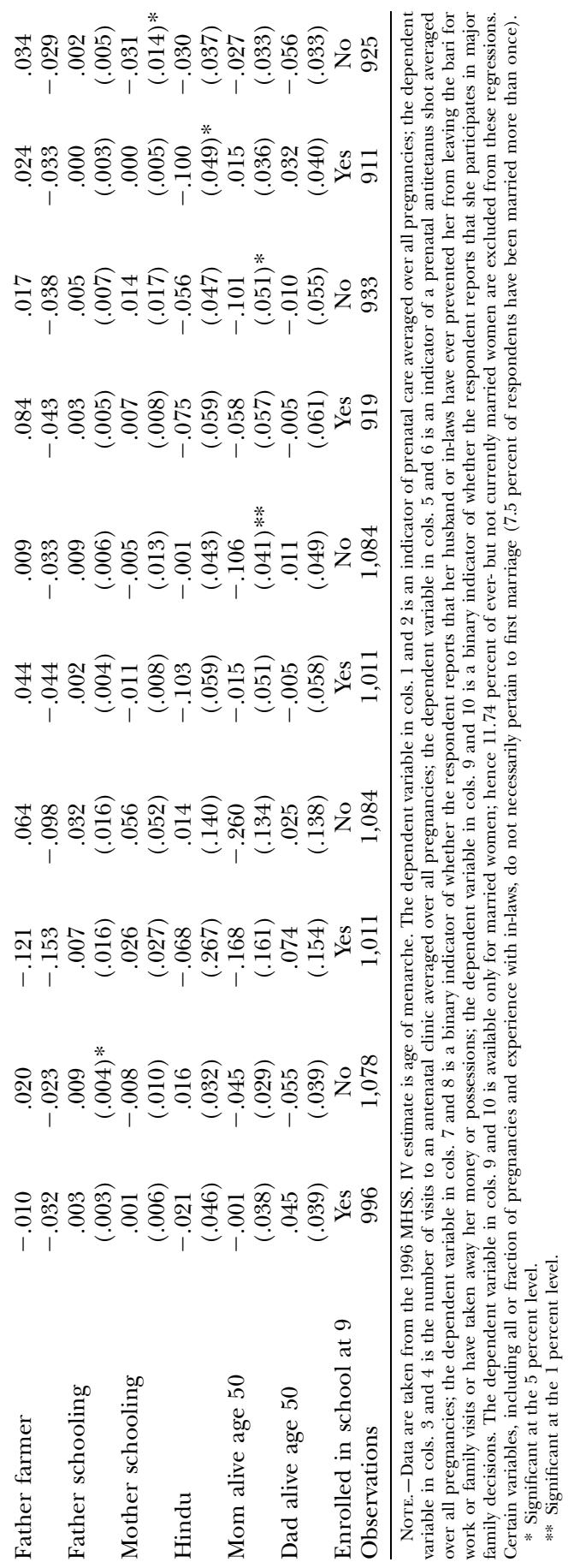


instance, by responding to health workers' suggestions for more frequent checkups. For instance, uneducated women who marry later may have greater freedom to leave the home for or spend money on health care services. Consistent with this story, results from regressions of two indicators of personal freedom on marriage age indicate that unschooled women who marry later face fewer restrictions by husbands and in-laws with respect to consumption and mobility (cols. 7 and 8 of table 5). The dependent variable in these regressions is constructed from the following MHSS survey questions: whether the respondent reports that her husband or in-laws have ever prevented her from leaving the bari for work or family visits or have taken away her money or possessions. Separate analysis on each of the four components reveals that the largest change comes from reducing the likelihood that women are prevented from leaving the bari for work. Since marriage age is not associated with a reduction in household restrictions among educated girls, there is no evidence that it operates through schooling. More likely the effect is related to convergence in age between spouses that accompanies later marriage.

\section{Spousal Quality}

The last stage of analysis examines trade-offs parents face in making decisions about marriage timing by looking at data on dowry payments at marriage and observable characteristics of spouses. The finding that marriage opportunities curtail schooling investment suggests that the benefits to girls of delaying marriage come at a cost to their families, presumably in terms of higher dowry payments or less desirable spouses. Anecdotally, in rural Bangladesh, dowries increase with each additional year that marriage is postponed because of the high demand for youthful brides.$^{26}$ Meanwhile, past findings from India confirm a strong positive association between dowry payments and suitability of the husband, measured in terms of his relative superiority in education and family SES (Halli 2003).

To explore how parents respond to these trade-offs, we estimate the dowry cost of later marriages using the same IV strategy from the previous section. We similarly explore how characteristics of spouses in terms of education level, age, and family wealth are related to marriage timing. If parents indeed spend more on daughters who marry later,

${ }^{26}$ Cited reasons for this preference include the beliefs that younger brides are $(a)$ more fertile, $(b)$ more likely to lack sexual experience, and $(c)$ easier for husbands and in-laws to control. Foster and Kahn (2000) argue that the increase in female age at marriage and corresponding reduction in average age differences between spouses as an equilibrating mechanism for demographic changes in the supply of spouses reflects a decrease in the demand for youth in the marriage market. 
TABLE 6

Marriage Market Outcomes

\begin{tabular}{|c|c|c|c|c|c|}
\hline & $\begin{array}{l}\text { Value of } \\
\text { Dowry } \\
(1)\end{array}$ & $\begin{array}{c}\text { Spouse } \\
\text { Highest } \\
\text { Grade } \\
\text { Passed }^{\text {a }} \\
\quad(2)\end{array}$ & $\begin{array}{c}\text { Spouse's } \\
\text { Father's } \\
\text { Education } \\
\text { (3) }\end{array}$ & $\begin{array}{c}\text { Spouse } \\
\text { Wealthier at } \\
\text { Marriage } \\
\text { (4) }\end{array}$ & $\begin{array}{l}\text { Spouse } \\
\text { Age } \\
(5)\end{array}$ \\
\hline Age of marriage & $\begin{array}{c}343.234 \\
(191.318)\end{array}$ & $\begin{array}{l}.047 \\
(.158)\end{array}$ & $\begin{array}{c}-.045 \\
(.111)\end{array}$ & $\begin{array}{c}-.006 \\
(.021)\end{array}$ & $\begin{array}{l}-.719 \\
(.452)\end{array}$ \\
\hline \multicolumn{6}{|l|}{ Age of marriage $\times$} \\
\hline In school at 9 & $\begin{array}{r}-652.643 \\
(385.634)\end{array}$ & $\begin{array}{c}-.139 \\
(.236)\end{array}$ & $\begin{array}{c}.000 \\
(.215)\end{array}$ & $\begin{array}{r}-.015 \\
(.031)\end{array}$ & $\begin{array}{c}.127 \\
(.695)\end{array}$ \\
\hline Height $(\mathrm{cm})$ & $\begin{array}{c}23.830 \\
(22.897)\end{array}$ & $\begin{array}{l}.016 \\
(.015)\end{array}$ & $\begin{array}{c}-.003 \\
(.011)\end{array}$ & $\begin{array}{c}-.003 \\
(.002)\end{array}$ & $\begin{array}{c}-.069 \\
(.041)\end{array}$ \\
\hline Age in years & $\begin{array}{l}-337.045 \\
\quad(52.907) * *\end{array}$ & $\begin{array}{c}-.063 \\
(.071)\end{array}$ & $\begin{array}{c}-.018 \\
(.053)\end{array}$ & $\begin{array}{r}-.009 \\
(.009)\end{array}$ & $\begin{array}{l}.626 \\
(.182) * *\end{array}$ \\
\hline $\begin{array}{l}\text { Contraceptive } \\
\text { intervention }\end{array}$ & $\begin{array}{l}764.413 \\
(274.842) * *\end{array}$ & $\begin{array}{l}.604 \\
(.195)^{* *}\end{array}$ & $\begin{array}{l}.146 \\
(.155)\end{array}$ & $\begin{array}{l}.004 \\
(.024)\end{array}$ & $\begin{array}{c}-.016 \\
(.484)\end{array}$ \\
\hline Value father's land & $\begin{array}{c}26.840 \\
(99.173)\end{array}$ & $\begin{array}{l}.097 \\
(.043)^{*}\end{array}$ & $\begin{array}{c}-.012 \\
(.045)\end{array}$ & $\begin{array}{l}.015 \\
(.007) *\end{array}$ & $\begin{array}{l}.188 \\
(.156)\end{array}$ \\
\hline Father business & $\begin{array}{c}1,459.563 \\
(821.427)\end{array}$ & $\begin{array}{c}-.111 \\
(.333)\end{array}$ & $\begin{array}{l}.116 \\
(.289)\end{array}$ & $\begin{array}{l}.078 \\
(.045)\end{array}$ & $\begin{array}{l}.689 \\
(.866)\end{array}$ \\
\hline Father farmer & $\begin{array}{c}349.843 \\
(397.548)\end{array}$ & $\begin{array}{l}.060 \\
(.258)\end{array}$ & $\begin{array}{c}-.178 \\
(.173)\end{array}$ & $\begin{array}{l}.153 \\
(.029)^{* *}\end{array}$ & $\begin{array}{l}.554 \\
(.633)\end{array}$ \\
\hline Father's schooling & $\begin{array}{c}42.967 \\
(46.388)\end{array}$ & $\begin{array}{l}.158 \\
(.028)^{* *}\end{array}$ & $\begin{array}{l}.174 \\
(.029) * *\end{array}$ & $\begin{array}{c}-.003 \\
(.004)\end{array}$ & $\begin{array}{l}.067 \\
(.083)\end{array}$ \\
\hline Mother's schooling & $\begin{array}{c}-8.590 \\
(107.511)\end{array}$ & $\begin{array}{l}.214 \\
(.053) * *\end{array}$ & $\begin{array}{l}.078 \\
(.057)\end{array}$ & $\begin{array}{l}.000 \\
(.007)\end{array}$ & $\begin{array}{c}-.129 \\
(.147)\end{array}$ \\
\hline Hindu & $\begin{array}{l}4,969.459 \\
(734.311) * *\end{array}$ & $\begin{array}{l}.337 \\
(.315)\end{array}$ & $\begin{array}{l}.486 \\
(.274)\end{array}$ & $\begin{array}{l}-.098 \\
(.037) * *\end{array}$ & $\begin{array}{l}2.356 \\
(.859) * *\end{array}$ \\
\hline Mom alive age 50 & $\begin{array}{c}-104.591 \\
(506.990)\end{array}$ & $\begin{array}{l}.594 \\
(.295)^{*}\end{array}$ & $\begin{array}{l}.576 \\
(.191)^{* *}\end{array}$ & $\begin{array}{l}.000 \\
(.035)\end{array}$ & $\begin{array}{c}-.125 \\
(.767)\end{array}$ \\
\hline Dad alive age 50 & $\begin{array}{c}660.828 \\
(364.151)\end{array}$ & $\begin{array}{l}.091 \\
(.307)\end{array}$ & $\begin{array}{c}-.037 \\
(.248)\end{array}$ & $\begin{array}{l}.055 \\
(.040)\end{array}$ & $\begin{array}{c}-.725 \\
(.759)\end{array}$ \\
\hline $\begin{array}{l}\text { Year of birth fixed } \\
\text { effects } \\
\text { Observations }\end{array}$ & $\begin{array}{c}\text { Yes } \\
1,846\end{array}$ & $\begin{array}{c}\text { No } \\
1,125\end{array}$ & $\begin{array}{c}\text { No } \\
1,559\end{array}$ & $\begin{array}{l}\text { No } \\
1,852\end{array}$ & $\begin{array}{c}\text { No } \\
1,852\end{array}$ \\
\hline $\begin{array}{l}\text { Note. - Data are take } \\
\text { interacted with in schoo } \\
\text { for clustering at the bar } \\
\text { dowry from your . . m } \\
1996 \text { value or the value } \\
\text { transfers such as jewelry } \\
\text { valuations. } \\
{ }^{\text {a }} \text { The number of obse } \\
{ }^{\mathrm{b}} \text { Asked of current spe } \\
\text { * Significant at the } 5 \\
\text { ** Significant at the }\end{array}$ & $\begin{array}{l}\text { om the } 1996 \mathrm{MH} \\
\text { age } 9 \text {. All regress } \\
\text { alue of dowry is c } \\
\text { iage?" asked of e } \\
\text { he time of marri } \\
\text { nd, and animals, } \\
\text { ions reflects a hi } \\
\text { s only, so col. } 3 \mathrm{i} \\
\text { cent level. } \\
\text { rcent level. }\end{array}$ & $\begin{array}{l}\text { cted from the } \\
\text { of the respor } \\
\text { is ambiguous } \\
\text { ge of birth } \\
\text { ate of nonres } \\
\text { des only wom }\end{array}$ & $\begin{array}{l}\text { icularly since } \\
\text { effects are us } \\
\text { for the depe }\end{array}$ & $\begin{array}{l}\text { menarche and } \\
\text { Robust standar } \\
\text { on: "What was } \\
\text { her the value g } \\
\text { hirds of dowrie } \\
\text { account for p } \\
\text { t variable. } \\
\text { ouse in } 1996 .\end{array}$ & $\begin{array}{l}\text { menarche } \\
\text { ors account } \\
\text { tal value of } \\
\text { reflects the } \\
\text { ade in-kind } \\
\text { al nominal }\end{array}$ \\
\hline
\end{tabular}

on the basis of the distribution of husbands' observable characteristics, we can assess whether the additional expenditure on later marriages is sufficient to buy their daughters positions in families of comparable quality to those of younger brides.

These estimates are presented in table 6 . Indeed, examination of the MHSS data suggests that the increased schooling accompanying late marriage comes at a substantial cost to the family. An IV estimate of the dowry cost of later marriages, presented in column 1, indicates that the wealth a girl brings into marriage increases by an average of 11 percent 
with each additional year that marriage is postponed, although the point estimate is significant only at the 10 percent level. Meanwhile, columns $2-5$ reveal no corresponding improvements in the characteristics of spouses in terms of education level, age, or family background (father's education and wealth relative to bride's father). This combination of marriage market outcomes indicates that the average additional dowry cost of late marriage is a good approximation of the decrease in female marriage market value that accompanies age in rural Bangladesh. The fact that late bloomers are no worse off in terms of observable spousal quality also potentially suggests a preference among parents for allocating marriage payments across daughters to equate their marital outcomes.

\section{General Equilibrium Analysis}

The previous empirical estimates address how a woman's educational choice changes if her individual constraint, age of menarche, changes. This corresponds to asking how the chosen level of education changes when varying an individual's constraint within the same equilibrium of the marriage market. Hence, it is not immediately obvious how this estimate corresponds to the overall impact of imposing a universal constraint, which leads the market to a new equilibrium. In this section we analyze the general equilibrium effects of such a regulation and use the results to estimate the impact of enforcing different possible legal ages of consent on female education.

\section{A. Theoretical Considerations}

Here we provide a discussion of how the demand for and supply of brides of different age levels are affected by imposing a minimum marriage age on the market. For a formal analysis, see the Appendix.

We think about the marriage market in Bangladesh as a large and impersonal market, where the demand for and supply of brides and grooms are equated through dowry payments (payments from the bride's family to the groom). These payments depend on both the groom's and the bride's observable characteristics. The characteristic we focus on is the bride's age: we assume that there is a different market dowry level for every possible bride age. It is well documented that men in Bangladesh have a preference for younger wives, and dowry payments are monotonically increasing in the bride's age. This creates an incentive for families to marry their daughters earlier since this decreases the dowry payment they are required to pay. Nevertheless, women are heterogeneous in what age they decide to get married, partly because some women have exogenous restrictions on marriage age (e.g., because they 
reach puberty at an older age) and partly because some families decide to delay marriage despite the increased cost (e.g., to let the daughter finish secondary school). In equilibrium, subject to the constraint imposed on marriage age by the age of puberty, we expect women who are more keen to marry early (or less keen to marry later) to enter the marriage market at a young age, marry men who are more eager to marry younger brides, and pay smaller levels of dowry. Similarly, we expect women who are more eager to marry later to enter the marriage market at an older age, marry men who are less eager to marry younger brides, and pay higher levels of dowry.

Enforcing a minimal legal marriage age $\bar{t}$ implies that women who in the absence of the regulation would have married younger than age $\bar{t}$ must decide whether they still want to marry and, if yes, then at what age satisfying the legal requirement. Similarly, men who in the absence of regulation would have married a bride younger than $\bar{t}$ have to decide whether they still want to marry and, if yes, then choose an optimal bride age among those that are legally permitted. In general, both the demand for and supply of brides older than $\bar{t}$ increase as a consequence of the regulation. However, in the absence of any restriction on preferences, there is no reason to expect a symmetric increase in the demand for and supply of all marriage ages older than $\bar{t}$. Hence, the prices (dowry levels) that cleared the market in the absence of regulation generally do not equilibrate the market after the regulation. To restore equilibrium, dowry levels corresponding to bride ages above $\bar{t}$ must change. These price changes in turn can change the marriage age decisions of even those women who in the absence of regulation would have married later than $\bar{t}$ and can change the bride age choices of those men who in the absence of regulation would have chosen a bride older than $\bar{t}$. Hence, marriage age decisions are effected even for those people who are not directly affected by the regulation.

To illustrate the previous point, consider an example in which there are two types of women, $w_{1}$ and $w_{2}$, and two types of men, $m_{1}$ and $m_{2}$. Assume that the number of women is equal to the number of men and that half of the women and men belong to each of the types above. There are three possible marriage ages of women: "very young," "young," and "mature." Both women and men have quasi-linear preferences in money. Men of type $m_{1}$ are more eager to acquire younger brides, and the utility they attain from marrying a very young, young, or mature bride is 150,100 , and 50 monetary units, respectively. Men of type $m_{2}$ attach utility levels 30,20 , and 10 to marrying a very young, young, or mature bride. In this example, assume that women reach puberty at a very young age, and hence all women are free to choose among all possible marriage ages. Women of type $w_{1}$ are indifferent between marrying at a young and at a very young age, both giving them a utility of 
20 monetary units; but they prefer to marry at a mature age, yielding a utility of 50 monetary units. For women of type $w_{2}$, getting married at a very young age gives a utility of 20 monetary units, getting married at a young age gives 40 monetary units, and getting married at a mature age gives 60 monetary units.

In this example, it is easy to verify that in any market equilibrium without regulation, women of type $w_{1}$ get married at a very young age (marrying men of type $m_{1}$ ), whereas women of type $w_{2}$ get married at a mature age (marrying men of type $m_{2}$ ), and they pay a dowry that is higher than what the other type of women pay by something between 30 and 40 monetary units (there is an indeterminacy in the marketclearing price due to the finite number of types). At this dowry premium level, women of type $w_{2}$ are willing to pay the higher dowry and wait to marry until reaching a mature age, whereas women of type $w_{1}$ would rather marry at a very young age and save on the dowry payment.

Suppose now that an age of consent law is imposed on the market, banning marriage at a very young age. It can be shown that in any market equilibrium, women of type $w_{2}$ (who in the absence of the regulation would have married at a mature age) marry at a young age (to men of type $m_{1}$ ), whereas women of type $w_{1}$ (who previously would have married at a very young age) marry at a mature age (to men of type $m_{2}$ ), and the market-clearing dowry premium for marrying at a mature age versus at a young age can be anything between 20 and 30 monetary units. Hence, the regulation imposed on the market switches the marriage order of different types of women.

The main feature of the above example is that women of type $w_{1}$ attain more utility from postponing marriage from a young age to a mature age than women of type $w_{2}$, whereas the relative order of utility gains is exactly the opposite when postponing marriage from a very young to a young age. In the Appendix we formally show that if the relative order of incremental utilities from postponing marriage by a year remains the same over different age levels for any two women, and similarly the relative order of incremental utilities from marrying a bride 1 year younger remains the same over the whole range of possible bride ages for any two men, then imposing a minimal legal marriage age does not change the marrying order of different women and men. ${ }^{27}$ In particular, if preferences satisfy this condition, then imposing a minimum legal age of marriage $x$ induces a very simple equilibrium adjustment: women who in the absence of regulation would have married younger marry exactly at the new minimum legal age, but the marriage timing

\footnotetext{
${ }^{27}$ This restriction on preferences is similar to supermodularity assumptions often imposed in the matching and search literature (see, e.g., Shimer and Smith 2000; Legros and Newman 2002)
} 
decisions of all other women remain unchanged. Moreover, the relative dowry premium for any additional year above $x$ remains the same as before; that is, relative equilibrium prices are not affected by the regulation.

The meaning and validity of the above assumptions depend on the reasons behind preferences over female marriage age. Consider first that the main motivation for preferring younger brides is to increase fertility by expanding the reproductive interval. ${ }^{28}$ Then the above restrictions are equivalent to assuming that (i) if for a man the incremental utility of the $k$ th child is higher than for another man, then the same relationship holds between incremental utilities of the $l$ th child as well, for any $k, l>0$; and (ii) there is a similar stable ordering with respect to women's incremental utilities/disutilities from having an additional child. If degree of spousal control rather than fertility drives preferences over bride's age, then the restriction is equivalent to assuming that if an increase in spousal control gives higher utility to one man relative to another at some level of control, then the same relationship holds at every level. Finally, if women's age of marriage choices are mainly driven by schooling, then the restriction implies that the order of women concerning incremental utilities from additional years of schooling does not depend on which school year is considered. One characteristic of the setting that makes this assumption more appealing is that degree completion is uncommon within the age period under study. Since secondary school starts around age 12 and ends around age 18, the additional years of schooling we examine are additional years of high school for the majority of our sample.

The fact that the adjustment from one equilibrium to another is so simple, provided that the above assumptions hold for preferences of women and men, implies that our estimates of how a woman's education level depends on what age she reaches puberty can be used in a straightforward way to assess the impact of imposing various possible minimum legal ages for marriage on aggregate female educational attainment.

\section{B. The Effect of a Minimum Legal Age of Marriage on Women's Education}

If equilibrium adjustment after imposing a minimum legal age of marriage $\bar{t}$ simply implies that women who would have married at a younger age marry at the new legal minimum age and that marriage time decisions of all other women are unaffected, then the following results

\footnotetext{
${ }^{28}$ While this is unlikely to be true given that fertility levels are nowhere near the biological maximum and very early childbearing can actually decrease future fertility, anecdotal evidence from many sources indicates that it is widely believed.
} 
hold for how the educational attainments of different women are affected by the legal change: (i) there is no effect on women who reach puberty after age $\bar{t}$, and (ii) for a woman who reaches puberty before age $\bar{t}$, the introduction of a minimum legal marriage age has the same effect as postponing her menarche to age $\bar{t}$. The introduction of a minimum marriage age imposes exactly the same lower bound on a woman's marriage age as if menarche was delayed, and since dowry premium levels above the minimum age do not change after a legal minimum age is imposed, optimal choices adjust in the same manner. Then if age of menarche is distributed among women independently of their preferences, a reduced-form estimate of the influence of delay in age of menarche on educational attainment can be used to provide an estimate of the average change in female education that arises from introducing distinct minimal legal ages of marriage. In particular, the effect on average female education of introducing minimal marriage age $\bar{t}>t_{\min }$ is

$$
\Delta \bar{E}_{t}=\sum_{t=t_{\min }}^{i-1} g(t) D_{t, \bar{t}},
$$

where $g$ is the distribution function of menarche and $D_{t, \bar{t}}$ is the average effect of postponing the age of menarche from $t$ to $\bar{t}$ on years of schooling. This result enables us to provide a structural estimate of the impact of age of consent laws. In particular, the $D_{i, j}$ terms can be recovered from an OLS regression of schooling attainment on age of menarche in which each menarcheal age is entered separately as a binary variable in the regression. Then (3) can be calculated for each possible $t_{\min }<$ $\bar{t}$ using information from the MHSS sample on the distribution of age of onset.

For the policy predictions we restrict the sample to women who were enrolled in school at age 9, under the presumption that future cohorts will have near-universal enrollment at early ages. According to these estimates, presented in table 7 , imposing a minimum marriage age of 13 would increase the average education of girls in Matlab by an average of only 0.024 year, whereas a legal minimum of 15 would increase average schooling by 0.219 year, with the local supply of schools held constant. The marginal effect of an age minimum is increasing through age 16 and then falls thereafter.

To understand the determinants of this marginal effect, it is useful to rewrite (3) as follows:

$$
\Delta \bar{E}_{t}=\sum_{t=t_{\min }}^{t-1}\left[\sum_{k=t_{\min }}^{t-1} g(k)\right] D_{t, t+1} .
$$


TABLE 7

Predicted Effect of Age of Consent Laws on Average Female Education iN MATLAB

\begin{tabular}{|c|c|c|c|c|c|c|c|}
\hline & \multicolumn{7}{|c|}{ AGE } \\
\hline & 11 & 12 & 13 & 14 & 15 & 16 & 17 \\
\hline Beta $_{\text {menarche at } t}$ & & $\begin{array}{c}.477 \\
(.68)\end{array}$ & $\begin{array}{c}.908 \\
(.58)\end{array}$ & $\begin{array}{c}.978 \\
(.59)\end{array}$ & $\begin{array}{l}1.251 \\
(.57)\end{array}$ & $\begin{array}{c}1.873 \\
(.61)\end{array}$ & $\begin{array}{c}1.674 \\
(.67)\end{array}$ \\
\hline$g(t)$ & .006 & .052 & .231 & .360 & .203 & .096 & .051 \\
\hline $\begin{array}{l}\text { Implied policy } \\
\text { effect of } t_{\min } \\
\left(\Delta \mu_{E}\right)\end{array}$ & & .003 & .024 & .044 & .219 & .745 & .557 \\
\hline
\end{tabular}

Note.-Data are taken from the 1996 MHSS. In the first row of the table, beta refers to the coefficient on an agespecific dummy for menarcheal age from a regression of schooling attainment on menarche. In row $2, g(t)$ is the distribution function of menarche at each age $t$. The implied policy effect is calculated according to eq. (3) in the text. Standard errors are in parentheses.

This formula reveals that the aggregate effect of increasing the minimum age depends on two factors: the number of women for whom it introduces a new constraint and the extent to which it affects the schooling choices of these women. As we saw in Section V, $D_{t, t+1}$, the incremental effect of an additional unmarried year for those who are affected by this change (the "treated" in the IV estimate), is substantial until age 16 and then significantly lower. However, this is partially offset by the fact that the number of women affected by the change, $\sum_{k=t_{\min }}^{t-1} g(k)$, is monotonically increasing. The higher the minimum legal age, the larger the number of women who reach puberty by that age. In particular, a substantial proportion of women reach puberty at age 16, increasing the marginal effect of setting the minimum legal age to 17 as opposed to 16 .

Nevertheless, the marginal effect of increasing the legal age is decreasing after age 16. According to our estimates, minimum age laws of 16 would generate similar schooling effects of minimum age laws of 17. This result has potentially important policy implications given the current predominance of high minimum marriage ages that appear to be too costly to enforce. A minimum marriage age of 16 would likely be far easier to enforce than the current target of 18 and still achieve most of the benefits in terms of female education.

\section{Conclusions}

This paper provides empirical evidence that the institution of adolescent marriage in developing countries reduces female education. When individual girls in rural Bangladesh are forced by biology to delay marriage, they attain significantly more schooling and are more likely to be literate. Under plausible assumptions about local marriage markets, 
these results indicate a 5-8 percent improvement in average female schooling from enforcing consent laws between ages 15 and 17.

The approach we introduce to estimate equilibrium adjustment effects from partial equilibrium results can potentially be used in other competitive market settings to assess the impact of imposing lower bounds on transactions. One could, for example, examine the effect of imposing minimum quality standards for a given product of heterogeneous quality. Our methodology would identify conditions under which exogenous individual-level variation in the marginal cost of product quality can be used to assess the impact of a universal quality regulation.

\section{Appendix}

\section{A. The Model}

We consider a marriage market with a set of women $W=\left\{w_{1}, \ldots, w_{n_{w}}\right\}$ and men $M=\left\{m_{1}, \ldots, m_{n_{m}}\right\}$. The model is static in that all individuals enter the marriage market at the same time; however, the same model can be derived from a dynamic model in which different cohorts enter the market each year. ${ }^{29}$ Therefore, the static model can be viewed as a simplification that provides a shortcut for the analysis. In the model, women choose levels of schooling and age of marriage, and men choose the age of their brides. Both men and women have the option not to marry. For simplicity, men's schooling decisions are assumed to be independent of marriage market outcomes and therefore are excluded from the analysis. Similarly, we assume that women do not care about the age of their spouses and do not explicitly model men's decisions concerning what age to marry. Note that although we talk about decisions of women and men in the marriage market, what we have in mind are the preferences and choices of the relevant decision makers such as parents.

Women can marry at ages $t_{\min }, t_{\min }+1, \ldots, t_{\max }$. Let $x_{i}$ denote the marriage age decision of $w_{i} \in W$, and let $y_{i}$ denote the decision of $m_{i} \in M$ on the age of his bride. For notational simplicity define $x_{i}$ (similarly $y_{i}$ ) to be $t_{\max }+1$ in the case in which the individual decides not to marry. Women are constrained in their marriage age decision by age of puberty: $x_{i} \geq p_{i}$, where $p_{i}$ is the age when $w_{i} \in W$ reaches puberty. With respect to schooling choices, let $e_{i}$ denote the years of education above $t_{\min }$ woman $w_{i}$ chooses. An important assumption in the model is that women's education levels are constrained by marriage. In particular, if woman $w_{i}$ decides to marry at age $t$, then $e_{i} \leq t-t_{\min }$.

We assume that the market is competitive and that the market-clearing prices are dowries women pay to grooms at marriage that depend only on bride's age. Let $d(t)$ denote the amount of dowry a woman has to pay if she decides to marry at age $t$. A woman who does not get married does not have to pay any dowry: $d\left(t_{\max }+1\right)=0$. Individuals' preferences are assumed to be quasi-linear in the amount of dowry paid or received.

The utility of woman $w_{i}$ from marriage net of transfers is $u_{i}\left(x_{i}, e_{i}\right)$. Given that

${ }^{29}$ See an earlier version of our paper. 
we assume that dowry depends on $x_{i}$ but not on $e_{i}$, we can simplify the utility function of women by substituting in the optimal level of education compatible with any given possible marriage time. Let $U_{i}(x)=\max _{0 \leq e \leq x-t_{\min }} u_{i}(x, e)$ for $x \in$ $\left(t_{\min }, \ldots, t_{\max }\right)$ and $U_{i}\left(t_{\max }+1\right)=\max _{0 \leq e} u_{i}\left(t_{\max }+1, e\right)$ (women who do not marry do not face any constraint on education). We assume that $U_{i}$ is concave but put no restriction on whether it is increasing or decreasing. The utility of man $m_{i}$ from marriage net of transfers is $V_{i}\left(y_{i}\right) .{ }^{30}$ We assume that $V_{i}$ is decreasing and concave, which implies that dowries have to be increasing in bride's age in order to clear the market. ${ }^{31}$

\section{B. Competitive Equilibria with and without a Minimum Legal Age of Marriage}

We define competitive equilibrium in the marriage market the standard way.

Definition. A competitive equilibrium of the marriage market consists of a vector of dowries $\hat{d}\left(t_{\min }\right), \ldots, \hat{d}\left(t_{\max }\right)$ and marriage age decisions $\hat{x}_{1}, \ldots, \hat{x}_{n_{m}}$, $\hat{y}_{1}, \ldots, \hat{y}_{n_{w v}}$ such that $\hat{x}_{i} \geq p_{i}$ for all $w_{i} \in W$ and the following conditions hold:

i. Given the vector of dowries, all men make an optimal choice and all women make a constrained optimal choice given that they can marry only after reaching puberty:

$$
U_{i}\left(\hat{x}_{i}\right)-\hat{d}\left(\hat{x}_{i}\right) \geq U_{i}\left(x_{i}\right)-\hat{d}(x) \quad \forall p_{i} \leq x \leq t_{\max }+1 \text { and } w_{i} \in W
$$

and

$$
V_{i}\left(\hat{y}_{i}\right)+\hat{d}\left(\hat{y}_{i}\right) \geq V_{i}(x)+\hat{d}(x) \quad \forall t_{\min } \leq x \leq t_{\max }+1 \text { and } m_{i} \in M .
$$

ii. The market clears for every possible marriage age:

$$
\#\left\{w_{i} \in W: \hat{x}_{i}=x\right\}=\#\left\{m_{i} \in M: \hat{y}_{i}=x\right\} \quad \forall t_{\min } \leq x \leq t_{\max } .
$$

We also consider markets in which there is a minimum legal marriage age $\bar{t}$ such that $t_{\min }<\bar{t} \leq t_{\max }$. In this case, dowries are specified only for marriage ages $\bar{t}, \ldots, t_{\max }$. A competitive equilibrium of the constrained market is defined analogously to that of the unconstrained market case.

In general, it is difficult to relate equilibrium marriage age choices in the unconstrained market to a market with an age minimum. In what follows, we impose the assumption that both women and men can be unambiguously ordered with respect to their incremental utilities from delaying marriage by 1 year. We also make an assumption that rules out nongeneric cases in which there exist a woman and man for whom increasing the bride's age at marriage by 1 year gives them exactly the opposite incremental utilities. The latter assumption is needed to guarantee uniqueness of equilibrium, which facilitates the comparison of unrestricted and restricted markets.

Assumption 1. For any $w_{i}, w_{i^{\prime}} \in W\left(i \neq i^{\prime}\right)$, it holds that if $U_{i}(x)-U_{i}(x+$

${ }^{30}$ In particular, the utility of a man who decides not to get married is $V_{i}\left(t_{\max }+1\right)$.

${ }^{31}$ Note that the model assumes that all women and men are of equal quality; in particular, any man is indifferent between marrying two brides of the same age. This assumption is made to keep the model simple. Our conclusions would remain the same if parallel marriage markets existed for different-quality women and men. 
1) $\geq U_{i^{\prime}}(x)-U_{i^{\prime}}(x+1)$ for some $t_{\min } \leq x \leq t_{\max }$, then

$$
U_{i}\left(x^{\prime}\right)-U_{i}\left(x^{\prime}+1\right)>U_{i^{\prime}}\left(x^{\prime}\right)-U_{i^{\prime}}\left(x^{\prime}+1\right) \quad \forall t_{\min } \leq x^{\prime} \leq t_{\max }-1 .
$$

Assumption 2. For any $m_{i}, m_{i^{\prime}} \in M\left(i \neq i^{\prime}\right)$, it holds that if $V_{i}(x)-V_{i}(x+$ $1) \geq V_{i^{\prime}}(x)-V_{i^{\prime}}(x+1)$ for some $t_{\min } \leq x \leq t_{\max }$, then

$$
V_{i}\left(x^{\prime}\right)-V_{i}\left(x^{\prime}+1\right)>V_{i^{\prime}}\left(x^{\prime}\right)-V_{i^{\prime}}\left(x^{\prime}+1\right) \quad \forall t_{\min } \leq x^{\prime} \leq t_{\max } .
$$

Assumption 3. For every $x \in\left\{t_{\min }, \ldots, t_{\max }\right\}$, it holds that there are no $w_{i} \in W$ and $m_{j} \in M$ such that $U_{i}(x)-U_{i}(x+1)=-\left[V_{i}(x)-V_{i}(x+1)\right]$.

Theorem 1. Assume that assumptions 1-3 hold. Then there exists a unique vector of marriage time choices $\hat{x}_{1}, \ldots, \hat{x}_{n_{m}}, \hat{y}_{1}, \ldots, \hat{y}_{n_{w}}$ that can be part of a competitive equilibrium. Similarly, for every minimal legal marriage age $\bar{t} \in$ $\left\{t_{\min }+1, \ldots, t_{\max }\right\}$, there exists a unique vector of marriage choices $\hat{x}_{1}^{i}, \ldots$, $\hat{x}_{n_{m}}^{i}, \hat{y}_{1}^{\bar{t}}, \ldots, \hat{y}_{n_{w w}}^{t}$ that can be part of a competitive equilibrium of the corresponding constrained market.

Proof. Before proving the theorem, we establish the following two lemmas.

Lemma 1. Assume that assumptions 1 and 2 hold. If $\hat{d}\left(t_{\min }\right), \ldots, \hat{d}\left(t_{\max }\right), \hat{x}_{1}$, $\ldots, \hat{x}_{n_{w}}, \hat{y}_{1}, \ldots, \hat{y}_{n_{m}}$ is a competitive equilibrium, then for every $x, x^{\prime} \in\left\{t_{\min }\right.$, $\left.\ldots, t_{\max }+1\right\}$ such that $x^{\prime}>x$, the following properties hold: \#\{wi $\in W: \hat{x}_{i}=$ $\left.x^{\prime}\right\} \neq 0$ implies $U_{i}\left(x^{\prime}\right)-U_{i}(x) \leq \hat{d}\left(x^{\prime}\right)-\hat{d}(x)$ for all $w_{i} \in W$ such that $\hat{x}_{i} \leq x$; $\#\left\{m_{i} \in M: \hat{y}_{i}=x^{\prime}\right\} \neq 0$ implies $V_{i}(x)-V_{i}\left(x^{\prime}\right) \geq \hat{d}\left(x^{\prime}\right)-\hat{d}(x)$ for all $m_{i} \in M$ such that $\hat{y}_{i} \leq x ; \quad \#\left\{w_{i} \in W: \hat{x}_{i}=x\right\} \neq 0$ implies $U_{i}\left(x^{\prime}\right)-U_{i}(x) \geq \hat{d}\left(x^{\prime}\right)-\hat{d}(x)$ for all $w_{i} \in W$ such that $\hat{x}_{i} \geq x^{\prime}$ and $p_{i} \leq x^{\prime}$; and $\#\left\{m_{i} \in M: \hat{y}_{i}=x\right\} \neq 0$ implies $V_{i}(x)-$ $V_{i}\left(x^{\prime}\right) \leq \hat{d}\left(x^{\prime}\right)-\hat{d}(x)$ for all $m_{i} \in M$ such that $\hat{y}_{i} \geq x^{\prime}$.

Proof. Suppose that the claim does not hold. Consider first the case in which there exists $m_{i} \in M$ and $x, x^{\prime} \in\left\{t_{\min }, \ldots, t_{\max }+1\right\}$ such that $\hat{y}_{i} \leq x, x<x^{\prime}$, $\#\left\{m_{j} \in M: \hat{y}_{j}=x\right\} \neq 0$, and $V_{i}(x)-V_{i}\left(x^{\prime}\right)<\hat{d}\left(x^{\prime}\right)-\hat{d}(x)$. If $\hat{y}_{i}=x$, then the previous inequality directly implies that $\hat{y}_{i}$ cannot be an optimal choice for $m_{i}$, a contradiction. Suppose now that $\hat{y}_{i}<x$. Since $\#\left\{m_{j} \in M: \hat{y}_{j}=x\right\} \neq 0$, there exists $m_{i^{\prime}} \in M$ such that $\hat{y}_{i^{\prime}}=x$. Since $\hat{y}_{i^{\prime}}=x$ and $\hat{y}_{i}<x$, it has to be that $V_{i^{\prime}}\left(\hat{y}_{i}\right)-$ $V_{i^{\prime}}(x) \leq V_{i}\left(\hat{y}_{i}\right)-V_{i}(x)$. Then assumption 1 implies that $V_{i^{\prime}}(x)-V_{i^{\prime}}\left(x^{\prime}\right) \leq V_{i}(x)-$ $V_{i}\left(x^{\prime}\right)$, which further implies that $V_{i^{\prime}}(x)-V_{i^{\prime}}\left(x^{\prime}\right)<\hat{d}\left(x^{\prime}\right)-\hat{d}(x)$, contradicting that $\hat{y}_{i^{\prime}}=x$ is an optimal choice for $m_{i^{\prime}}$. Consider next the case in which there exists $m_{i} \in M$ and $x, x^{\prime} \in\left\{t_{\min }, \ldots, t_{\max }+1\right\}$ such that $\hat{y}_{i} \geq x^{\prime}, x<x^{\prime}, \#\left\{m_{j} \in M: \hat{y}_{j}=\right.$ $\left.x^{\prime}\right\} \neq 0$, and $V_{i}(x)-V_{i}\left(x^{\prime}\right)>\hat{d}\left(x^{\prime}\right)-\hat{d}(x)$. If $\hat{y}_{i}=x^{\prime}$, then the previous inequality directly implies that $\hat{y}_{i}$ cannot be an optimal choice for $m_{i}$, a contradiction. Suppose now that $\hat{y}_{i}>x^{\prime}$. Since $\#\left\{m_{j} \in M: \hat{y}_{j}=x^{\prime}\right\} \neq 0$, there exists $m_{i^{\prime}} \in M$ such that $\hat{y}_{i^{\prime}}=x^{\prime}$. Since $\hat{y}_{i^{\prime}}=x^{\prime}$ and $\hat{y}_{i}>x^{\prime}$, it has to be that $V_{i^{\prime}}\left(x^{\prime}\right)-V_{i^{\prime}}\left(\hat{y}_{i}\right) \geq V_{i}\left(x^{\prime}\right)-$ $V_{i}\left(\hat{y}_{i}\right)$. Then assumption 1 implies that $V_{i^{\prime}}(x)-V_{i^{\prime}}\left(x^{\prime}\right) \geq V_{i}(x)-V_{i}\left(x^{\prime}\right)$, which further implies that $V_{i^{\prime}}(x)-V_{i^{\prime}}\left(x^{\prime}\right)>\hat{d}\left(x^{\prime}\right)-\hat{d}(x)$, contradicting that $\hat{y}_{i^{\prime}}=x^{\prime}$ is an optimal choice for $i^{\prime}$. This proves that the corresponding claims for women are analogous to the above, from assumption 1. QED

Lemma 2. Assume that assumptions 1 and 2 hold and that there is a minimum legal age of marriage $\bar{t} \in\left\{t_{\min }+1, \ldots, t_{\max }-1\right\}$. If $\hat{d}(\bar{t}), \ldots, \hat{d}\left(t_{\max }\right), \hat{x}_{1}$, $\ldots, \hat{x}_{n_{w}}, \hat{y}_{1}, \ldots, \hat{y}_{n_{m}}$ is a competitive equilibrium, then for every $x, x^{\prime} \in\{\bar{t}, \ldots$, 
$\left.t_{\max }\right\}$ such that $x^{\prime}>x$ and $\#\left\{w_{i} \in W: \hat{x}_{i}=x^{\prime}\right\} \neq 0$, the following assumptions hold:

$$
U_{i}(x)-U_{i}\left(x^{\prime}\right) \leq \hat{d}\left(x^{\prime}\right)-\hat{d}(x) \quad \forall w_{i} \in W \text { such that } \hat{x}_{i} \leq x
$$

and

$$
V_{i}\left(x^{\prime}\right)-V_{i}(x) \geq \hat{d}\left(x^{\prime}\right)-\hat{d}(x) \quad \forall m_{i} \in M \text { such that } \hat{y}_{i} \leq x .
$$

Furthermore, for every $x, x^{\prime} \in\left\{\bar{x}, \ldots, t_{\max }\right\}$ such that $x^{\prime}>x$ and $\#\left\{j \in W: \hat{x}_{j}=\right.$ $x\} \neq 0$, the following assumptions hold:

$$
U_{i}(x)-U_{i}\left(x^{\prime}\right) \geq \hat{d}\left(x^{\prime}\right)-\hat{d}(x) \quad \forall w_{i} \in W \text { such that } \hat{x}_{i} \geq x^{\prime} \text { and } m_{i} \leq x^{\prime}
$$

and

$$
V_{i}\left(x^{\prime}\right)-V_{i}(x) \leq \hat{d}\left(x^{\prime}\right)-\hat{d}(x) \quad \forall m_{i} \in M \text { such that } \hat{y}_{i} \geq x^{\prime} \text { and } m_{i} \leq x^{\prime} .
$$

Proof. Analogous to the proof of lemma 1.

Proof of theorem 1. Standard arguments establish the existence of a competitive equilibrium. Suppose that the assumptions of the theorem hold, and let $\hat{d}(\bar{t})$, $\ldots, \hat{d}\left(t_{\max }\right), \hat{x}_{1}, \ldots, \hat{x}_{n_{w}}, \hat{y}_{1}, \ldots, \hat{y}_{n_{m}}$ and $\hat{d}(\bar{t}), \ldots, \hat{\hat{d}}\left(t_{\max }\right), \hat{\hat{x}}_{1}, \ldots, \hat{x}_{n_{w}}, \hat{y}_{1}, \ldots, \hat{y}_{n_{m}}$ be two competitive equilibria of the marriage market with minimum marriage age $\bar{t} \in\left\{t_{\min }, \ldots, t_{\max }\right\}$, where $\bar{t}=t_{\min }$ refers to the unrestricted market.

Reindex women and men such that $U_{i}(x)-U_{i}\left(x^{\prime}\right)>U_{i^{\prime}}(x)-U_{i^{\prime}}\left(x^{\prime}\right)$ and $V_{i}(x)-V_{i}\left(x^{\prime}\right)<V_{i^{\prime}}(x)-V_{i^{\prime}}\left(x^{\prime}\right)$ whenever $i^{\prime}<i$ and $x<x^{\prime}$. Assumptions 1 and 2 imply that there is a reindexing like that. Then we claim that if $x_{1}, \ldots, x_{n_{w}}, y_{1}$, $\ldots, y_{n_{m}}$ constitutes a competitive equilibrium with some dowry vector, then $i^{\prime}<$ $i$ implies $y_{i^{\prime}} \leq y_{i}$, and $i^{\prime}<i$ and $p_{i^{\prime}} \leq x_{i}$ imply $x_{i^{\prime}} \leq x_{i^{\prime}}$. To see this, note that $y_{i^{\prime}}>y_{i}$ for $i^{\prime}<i$ contradicts that both $x_{i^{\prime}}$ and $x_{i}$ are optimal choices under the same dowry vector. Similarly, $x_{i^{\prime}}>x_{i}$ and $x_{i} \geq p_{i^{\prime}}$ for $i^{\prime}<i$ contradict that both $x_{i^{\prime}}$ and $x_{i}$ are optimal choices under the same dowry vector.

Suppose now that $\hat{x}_{i}=\hat{y}_{j}$ and $\hat{\hat{x}}_{i}>\hat{\hat{y}}_{j}$. The above results then imply that $\hat{\hat{y}}_{j}<p_{i}$ and that there exists $i^{\prime}>i$ such that $\hat{x}_{i^{\prime}}>\hat{y}_{j}$ and $\hat{\hat{x}}_{i^{\prime}}=\hat{\hat{y}}_{j}$. Then $\hat{d}\left(\hat{x}_{i^{\prime}}\right)-\hat{d}\left(\hat{y}_{j}\right) \leq$ $U_{i^{\prime}}\left(\hat{y}_{j}\right)-U_{i^{\prime}}\left(\hat{x}_{i^{\prime}}\right)$. By lemma 1 this implies $\hat{d}\left(\hat{y}_{j}\right)-\hat{d}\left(\hat{\hat{y}}_{j}\right) \leq U_{i^{\prime}}\left(\hat{y}_{j}\right)-U_{i^{\prime}}\left(\hat{\hat{y}}_{j}\right)$. Furthermore, since $\hat{y}_{j}$ is an optimal choice for $m_{j}$ given $\hat{d}(\bar{x}), \ldots, \hat{d}\left(t_{\max }\right), \hat{d}\left(\hat{y}_{j}\right)-$ $\hat{d}\left(\hat{\hat{y}}_{j}\right) \geq V_{j}\left(\hat{\hat{y}}_{j}\right)-V_{j}\left(\hat{y}_{j}\right)$. Combining the previous inequalities implies $V_{j}\left(\hat{\hat{y}}_{j}\right)-$ $V_{j}\left(\hat{y}_{j}\right) \leq U_{i^{\prime}}\left(\hat{y}_{j}\right)-U_{i^{\prime}}\left(\hat{\hat{y}}_{j}\right)$. This can be compatible with $\hat{\hat{x}}_{i^{\prime}}=\hat{\hat{y}}_{j}$ only if $V_{j}\left(\hat{\hat{y}}_{j}\right)-$ $V_{j}\left(\hat{y}_{j}\right)=U_{i^{\prime}}\left(\hat{y}_{j}\right)-U_{i^{\prime}}\left(\hat{y}_{j}\right)$. But this, together with concavity of $V_{j}$ and $U_{i^{\prime}}$, would imply $V_{j}\left(\hat{\hat{y}}_{j}\right)-V_{j}\left(\hat{\hat{y}}_{j}+1\right)=U_{i^{\prime}}\left(\hat{\hat{y}}_{j}+1\right)-U_{i^{\prime}}\left(\hat{\hat{y}}_{j}\right)$, contradicting assumption 3. Therefore, $\hat{x}_{i}=\hat{y}_{j}$ implies $\hat{x}_{i} \leq \hat{y}_{j}$. The same arguments establish that $\hat{\hat{x}}_{i}=\hat{\hat{y}}_{j}$ implies $\hat{x}_{i} \leq \hat{y}_{j}$. Combining these establishes that $\hat{x}_{i}=\hat{y}_{j} \Leftrightarrow \hat{\hat{x}}_{i}=\hat{\hat{y}}_{j}$.

Suppose now that $\hat{y}_{i} \neq \hat{\hat{y}}_{i}$ for some $m_{i} \in M$. Without loss of generality, let $\hat{y}_{i}<\hat{\hat{y}}_{i}$. Let $w_{j} \in W$ be such that $\hat{x}_{j}=\hat{x}_{i}$ (the existence of such a woman is guaranteed by the market-clearing condition). The result in the previous paragraph implies that $\hat{\hat{x}}_{j}=\hat{y}_{i}$. Since $\hat{y}_{i}$ is optimal given $\hat{d}(\bar{t}), \ldots, \hat{d}\left(t_{\max }\right), V_{i}\left(\hat{y}_{i}\right)-V_{i}\left(\hat{\hat{y}}_{i}\right) \geq$ $\hat{d}\left(\hat{\hat{y}}_{i}\right)-\hat{d}\left(\hat{y}_{i}\right)$. Since $\hat{\hat{y}}_{i}$ is optimal given $\hat{d}(\bar{t}), \ldots, \hat{\hat{d}}\left(t_{\max }\right), V_{i}\left(\hat{y}_{i}\right)-V_{i}\left(\hat{\hat{y}}_{i}\right) \leq \hat{\hat{d}}\left(\hat{\hat{y}}_{i}\right)-$ $\hat{d}\left(\hat{y}_{i}\right)$. Since $\hat{x}_{j}$ is optimal given $\hat{d}(\bar{t}), \ldots, \hat{d}\left(t_{\max }\right), U_{j}\left(\hat{\hat{y}}_{i}\right)-U_{\dot{\hat{\lambda}}}\left(\hat{y}_{i}\right) \leq \hat{d}\left(\hat{\hat{y}}_{i}\right)-\hat{d}\left(\hat{y}_{i}\right)$. Since $\hat{\hat{x}}_{j}$ is optimal given $\hat{d}(\bar{t}), \ldots, \hat{\hat{d}}\left(t_{\max }\right), U_{j}\left(\hat{\hat{y}}_{i}\right)-U_{j}\left(\hat{y}_{i}\right) \geq \hat{\hat{d}}\left(\hat{\hat{y}}_{i}\right)-\hat{\hat{d}}\left(\hat{y}_{i}\right)$. These four 
inequalities can hold simultaneously only if

$$
V_{i}\left(\hat{y}_{i}\right)-V_{i}\left(\hat{\hat{y}}_{i}\right)=\hat{d}\left(\hat{\hat{y}}_{i}\right)-\hat{d}\left(\hat{y}_{i}\right)=\hat{d}\left(\hat{\hat{y}}_{i}\right)-\hat{d}\left(\hat{y}_{i}\right)=U_{j}\left(\hat{\hat{y}}_{i}\right)-U_{j}\left(\hat{y}_{i}\right)
$$

Concavity of $V_{i}$ and $U_{j}$ then implies $V_{i}\left(\hat{y}_{i}\right)-V_{i}\left(\hat{y}_{i}+1\right)=U_{j}\left(\hat{y}_{i}+1\right)-U_{j}\left(\hat{y}_{i}\right)$. Therefore, $\hat{y}_{i}=\hat{y}_{i}$ for all $m_{i} \in M$. Then the result obtained in the previous paragraph establishes the claim. QED

Now we establish the main theorem, namely, that the introduction of a minimum age changes equilibrium decisions of women and men in a simple manner if the above assumptions hold. In particular, those individuals who would have married earlier than the minimum legal age in the unconstrained market get married exactly at the minimum legal age in the constrained market, whereas the rest of the women and men get married at the same time that they would have in the unconstrained market.

Theorem 2. Assume that assumptions 1-3 hold. Let the unique vector of marriage choices in competitive equilibrium be $\hat{x}_{1}, \ldots, \hat{x}_{n_{m}}, \hat{y}_{1}, \ldots, \hat{y}_{n_{w}}$. Then for any minimal binding age $\bar{t} \in\left\{t_{\min }+1, \ldots, t_{\max }\right\}$, the unique vector of marriage choices $\hat{x}_{1}^{\bar{l}}, \ldots, \hat{x}_{n_{m}}^{\bar{i}}, \hat{y}_{1}^{\bar{l}}, \ldots, \hat{y}_{n_{w}}^{i}$ in competitive equilibrium of the constrained market with minimum legal age $\bar{t}$ satisfies $\hat{x}_{i}^{\bar{t}}=\bar{t}$ if $\hat{x}_{i}<\bar{t}$ and $\hat{x}_{i}^{\bar{t}}=\hat{x}_{i}$ if $\hat{x}_{i} \geq \bar{t}$ for all $w_{i} \in W$. Similarly, $\hat{y}_{i}^{\bar{t}}=\bar{t}$ if $\hat{y}_{i}<\bar{t}$ and $\hat{y}_{i}^{\bar{t}}=\hat{y}_{i}$ if $\hat{y}_{i} \geq \bar{t}$ for all $m_{i} \in W$.

Proof. For $\bar{t}=t_{\max }$ the claim is trivial. Let $\bar{t} \in\left\{t_{\min }+1, \ldots, t_{\max }-1\right\}$. Let $\hat{d}\left(t_{\min }\right), \ldots, \hat{d}\left(t_{\max }\right)$ be a vector of endowments that together with $\hat{x}_{1}, \ldots, \hat{x}_{n_{w}}$, $\hat{y}_{1}, \ldots, \hat{y}_{n_{m}}$ constitute a competitive equilibrium of the unrestricted market (as noted in the proof of theorem 1, a competitive equilibrium always exists).

Let $W^{*}=\left\{w_{i} \in W: \hat{x}_{i}<\bar{t}\right\}$ and let $M^{*}=\left\{m_{i} \in M: \hat{y}_{i}<\bar{t}\right\}$. Define $x^{*}$ to be the minimal $x$ such that $x \geq \bar{t}$ and $\#\left\{m_{i} \in W: \hat{y}_{i}=x\right\} \neq 0$. Let $\Delta(x)=$ $\min _{m_{i} \in M^{*}}\left[U_{i}(x)-U_{i}\left(x^{*}\right)\right]$ for all $x \in\left\{\bar{t}, \ldots, x^{*}-1\right\}$. Construct a new dowry vector $\hat{d}^{\prime}$ such that $\hat{d}^{\prime}(x)=\hat{d}(x)$ for all $x \geq x^{*}$ and $\hat{d}^{\prime}(x)=\hat{d}\left(x^{*}\right)-\Delta(x)$ for all $x^{*}>x>$ $\bar{t}$. We claim that $\hat{d}^{\prime}$, together with $\hat{x}_{1}^{\bar{t}}, \ldots, \hat{x}_{n_{w}}^{i}, \hat{y}_{1}^{i}, \ldots, \hat{y}_{n_{m}}^{\bar{t}}$ as constructed in the theorem, constitutes a competitive equilibrium of the marriage market with

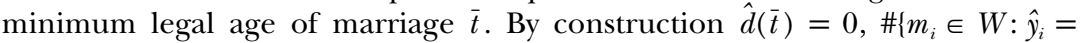
$x\}=\#\left\{w_{i} \in W: \hat{x}_{i}=x\right\}$ for all $\bar{t} \leq x \leq t_{\text {max }}$, and $\hat{x}_{i} \geq p_{i}$ for all $w_{i} \in W$. Furthermore, note that $\hat{d}^{\prime}(x)-\hat{d}^{\prime}\left(x^{\prime}\right)=\hat{d}(x)-\hat{d}\left(x^{\prime}\right)$ for all $x, x^{\prime} \in\left\{x^{*}, \ldots, t_{\max }\right\}$. But then the starting assumption that $\hat{x}_{1}, \ldots, \hat{x}_{n_{w}}, \hat{y}_{1}, \ldots, \hat{y}_{n_{m}}, \hat{d}\left(t_{\min }\right), \ldots, \hat{d}\left(t_{\max }\right)$ constitutes a competitive equilibrium of the unconstrained marriage market implies that if for some $w_{i} \in W \hat{x}_{i} \geq \bar{x}$, then $\hat{x}_{i}^{i}=\hat{x}_{i}$ is a better decision than any other choice from $\left\{x^{*}, \ldots, t_{\max }\right\}$ if the dowry vector is $\hat{d}^{\prime}$. By assumption 1 and the definition of $\hat{d}^{\prime}(x)$ for $x^{*}>x \geq \bar{t}, \hat{x}_{i}^{\bar{t}}$ is a better decision than any $x$ for which $x^{*}>x \geq \bar{t}$ given dowry vector $\hat{d}^{\prime}$. This concludes that $\hat{x}_{i}^{\bar{t}}$ is an optimal decision for $w_{i} \in W / W^{*}$ in the constrained market with minimum legal marriage age $\bar{t}$ under dowry vector $\hat{d}^{\prime}$. It is completely analogous to show, using assumption 2 , that $\hat{y}_{i}^{\bar{t}}$ is an optimal decision for $m_{i} \in M / M^{*}$ in the constrained market with minimum legal marriage age $\bar{t}$ given dowry vector $\hat{d}^{\prime}$. Furthermore, lemma 2 implies that $U_{i}(x)-$ $U_{i}\left(x^{*}\right)<\hat{d}(x)-\hat{d}\left(x^{*}\right)=\hat{d}^{\prime}(x)-\hat{d}^{\prime}\left(x^{*}\right)$ for all $x \in\left\{x^{*}+1, \ldots, t_{\max }+1\right\}$ and $w_{i} \in$ $W^{*}$ and that $V_{i}\left(x^{*}\right)-V_{i}(x) \geq \hat{d}(x)-\hat{d}\left(x^{*}\right)=\hat{d}^{\prime}(x)-\hat{d}^{\prime}\left(x^{*}\right)$ for all $x \in\left\{x^{*}+1\right.$, $\left.\ldots, t_{\max }+1\right\}$ and $m_{i} \in M^{*}$. By assumption 2 and the definition of $\hat{d}^{\prime}(x)$ for $x^{*}>x \geq \bar{t}$, it is also true that $V_{i}(\bar{t})-V_{i}\left(x^{*}\right) \geq \hat{d}^{\prime}\left(x^{*}\right)-\hat{d}^{\prime}(\bar{t})=\hat{d}^{\prime}\left(x^{*}\right)$. This concludes that $\hat{x}_{i}^{i}$ is an optimal decision for $m_{i} \in M^{*}$ in the constrained market with 
minimum legal marriage age $\bar{t}$ under dowry vector $\hat{d}^{\prime}$. Consider now any $m_{j} \in$ $W^{*}$. Define $x^{* *}$ to be the maximal $x$ such that $x<\bar{t}$ and $\#\left\{w_{i} \in W: \hat{x}_{i}=x\right\} \neq 0$. By lemma $2, U_{j}\left(x^{*}\right)-U_{j}\left(x^{* *}\right) \leq \hat{d}\left(x^{* *}\right)-\hat{d}\left(x^{*}\right)$. Also by lemma $2, V_{i}\left(x^{* *}\right)-$ $V_{i}\left(x^{*}\right) \geq \hat{d}\left(x^{* *}\right)-\hat{d}\left(x^{*}\right)$ for all $m_{i} \in M^{*}$. This implies $V_{i}\left(x^{* *}\right)-V_{i}\left(x^{*}\right) \geq U_{j}\left(x^{*}\right)-$ $U_{j}\left(x^{* *}\right)$ for all $m_{i} \in M^{*}$. The concavity of the utility functions and $x^{* *}<\bar{t} \leq x^{*}$ then imply $V_{i}(\bar{t})-V_{i}\left(x^{*}\right) \geq U_{j}\left(x^{*}\right)-U_{j}(\bar{t})$ for all $m_{i} \in M^{*}$. Then by the construction of $\hat{d}^{\prime}$, it holds that $U_{j}\left(x^{*}\right)-U_{j}(\bar{t}) \leq \hat{d}^{\prime}(\bar{t})-\hat{d}^{\prime}\left(x^{*}\right)$. Combining the above findings concludes that $\hat{x}_{j}^{i}$ is an optimal decision for $w_{j} \in W^{*}$ in the constrained market with minimum legal marriage age $\bar{t}$ given dowry vector $\hat{d}^{\prime}$. This establishes that $\hat{x}_{1}^{\bar{t}}, \ldots, \hat{x}_{n_{w}}^{\bar{i}}, \hat{y}_{1}^{\bar{i}}, \ldots, \hat{y}_{n_{m}}^{\bar{i}}$, and $\hat{d}^{\prime}$ constitute a competitive equilibrium of the marriage market with minimum legal age of marriage $\bar{t}$. Then by theorem 1 , marriage time choices in every competitive equilibrium of the constrained market with minimum legal marriage age $\bar{t}$ are $\hat{x}_{1}^{\bar{t}}, \ldots, \hat{x}_{n_{w}}^{\bar{t}}, \hat{y}_{1}^{\bar{t}}, \ldots, \hat{y}_{n_{m}}^{\bar{t}}$ QED

\section{References}

Aguilar, E., L. Pinilla, R. Guisado, D. Gonzalez, and F. Lopez. 1984. "Relation between Body Weight, Growth Rate, Chronological Age and Puberty in Male and Female Rats." Revista Española de Fisiologia 40 (March): 83-86.

Ahima, Rexford S., Jody Dushay, Sarah N. Flier, Daniel Prabakaran, and Jeffrey S. Flier. 1997. "Leptin Accelerates the Onset of Puberty in Normal Female Mice." J. Clinical Investigation 99 (February): 391-95.

Ahima, Rexford S., et al. 1996. "Role of Leptin in the Neuroendocrine Response to Fasting." Nature 382 (July 18): 250-52.

Andersson, Anna-Maria, and Niels E. Skakkebaek. 1999. "Exposure to Exogenous Estrogens in Food: Possible Impact on Human Development and Health." European J. Endocrinology 140 (June): 477-85.

Arends-Kuenning, Mary, and Sajeda Amin. 2004. "Schooling Incentive Programs and Children's Activities: The Case of Bangladesh." Comparative Educ. Rev. 48 (3): 295-317.

Barash, Ilona A., et al. 1996. "Leptin Is a Metabolic Signal to the Reproductive System.” Endocrinology 137 (July): 3144-47.

Barkat, Abul, and Murtaza Majid. 2003. "Adolescent Reproductive Health in Bangladesh: Status, Policies, Programs and Issues.” POLICY Project Report, U.S. Agency for International Development Asia/Near East Bureau, Washington, DC.

Bates, Lisa M., Farzana Islam, Khairul Islam, and Sidney Ruth Schuler. 2004. "Legal Registration of Marriage in Bangladesh: An Intervention to Strengthen Women's Economic and Social Position and Protect Them against Domestic Violence?” Manuscript, Acad. Educ. Development, Washington, DC.

Begum, Lutfa. 2003. "Meaning Given to Adolescents' Reproductive Health in Bangladesh." J. Population 9 (January): 81-103.

Bosch, Alinda. 2001. "Reproductive Health of Adolescents in Rural Bangladesh." PhD diss., Netherlands Interdisciplinary Demographic Inst.

Bronson, F. H. 1987. "Puberty in Female Rats: Relative Effect of Exercise and Food Restriction." American J. Physiology-Regulatory, Integrative and Comparative Physiology 252, no. 1, pt. 2 (January): R140-R144.

Bruce, Judith, Paul Hewett, and Cynthia B. Lloyd. 2001. "Facts about Adolescents from the Demographic and Health Survey: Bangladesh 1996-1997." Report, Population Council, New York. 
Bullough, Vern L. 1981. "Age at Menarche: A Misunderstanding." Science 213 (July 17): 365-66.

Cambridge Encyclopedia of Growth and Development. 1998. Edited by S. J. Ulijaszek, F. E. Johnston, and M. A. Preece. Cambridge: Cambridge Univ. Press.

Campbell, Benjamin C., and J. Richard Udry. 1995. "Stress and Age at Menarche of Mothers and Daughters." J. Biosocial Sci. 27 (April): 127-34.

Casey, V. A., J. T. Dwyer., K. A. Coleman, E. A. Krall, J. Gardner, and I. Valadian. 1991. "Accuracy of Recall by Middle-Aged Participants in a Longitudinal Study of Their Body Size and Indices of Maturation Earlier in Life." Ann. Human Biology 18 (April): 155-66.

Chehab, Farid F., Khalid Mounzih, Ronghua Lu, and Mary E. Lim. 1997. "Early Onset of Reproductive Function in Normal Female Mice Treated with Leptin." Science 275 (January 3): 88-90.

Cheung, Clement C., Janice E. Thornton, Joseph L. Kuipjer, David S. Weigle, Donald K. Clifton, and Robert A. Steiner. 1997. "Leptin Is a Metabolic Gate for the Onset of Puberty in the Female Rat." Neuroendocrinology 138 (February): 855-58.

Cheung, Clement C., Janice E. Thornton, Shafeena D. Nurani, Donald K. Clifton, and Robert A. Steiner. 2001. "A Reassessment of Leptin's Role in Triggering the Onset of Puberty in the Rat and Mouse." Neuroendocrinology 74 ( January): 12-21.

Chowdhury, S., et al. 2000. "Nutritional Status and Age at Menarche in a Rural Area of Bangladesh." Ann. Human Biology 27 (3): 249-56.

Clark, A. S., M. C. Kelton, and A. C. Whitney. 2000. "Chronic Administration of Anabolic Steroids Disrupts Pubertal Onset and Estrous Cyclicity in Rats." Biology of Reproduction 68 (February): 465-71.

Cooper, Ralph L., and Robert J. Kavlock. 1997. "Endocrine Disruptors and Reproductive Development: A Weight-of-Evidence Overview.” J. Endocrinology 152 (February): 159-66.

Damon, Albert, Selma T. Damon, Robert B. Reed, and Isabelle Valadian. 1969. "Age at Menarche of Mothers and Daughters, with a Note on Accuracy of Recall." Human Biology 41 (May): 160-75.

Der, Raymond, Zuhal Fahim, David Hilderbrand, and Mostafa Fahim. 1974. "Combined Effect of Lead and Low Protein Diet on Growth, Sexual Development, and Metabolism in Female Rats." Res. Communications Chemical Pathology and Pharmacology 9 (December): 723-38.

Dorn, Lorah D., Editha D. Nottelmann, Elizabeth J. Susman, Gale Inoff-Germain, Gordon B. Cutler Jr., and George P. Chrousos. 1999. "Variability in Hormone Concentrations and Self-Reported Menstrual Histories in Young Adolescents: Menarche as an Integral Part of a Developmental Process." J. Youth and Adolescence 28 (June): 283-304.

Dougherty, E. J., K. Chartisathian, K. G. Kitchens, M. A. Vasallo, and H. I'Anson. 1998. "Determination of the Effect of Glucoprivation on the Onset of Puberty in Female Rats." Biology of Reproduction 58 (suppl 1; January): 138.

Ellis, Bruce J. 2004. "Timing of Pubertal Maturation in Girls: An Integrated Life History Approach.” Psychological Bull. 130 (6): 920-58.

Engelbregt, M. J., M. M. van Weissenbruch, C. Popp-Snijders, and H. A. Delemarre-van de Waal. 2002. "Delayed First Cycle in Intrauterine GrowthRetarded and Postnatally Undernourished Female Rats: Follicular Growth and Ovulation after Stimulation with Pregnant Mare Serum Gonadotropin at First Cycle." J. Endocrinology 173 (May): 297-304.

Field, Erica. 2007. "Review of Human Evidence on the Relationship between 
Nutrition and Menarche." Manuscript, Harvard Univ., http://www .economics.harvard.edu/faculty/field/files/Field_Metaanalysis.pdf.

Fishbein, Siv. 1977. "Onset of Puberty in MZ and DX Twins." Acta Geneticae Medicae et Gemallologiae 26 (2): 151-58.

Fogel, Robert F. 1990. "The Conquest of High Mortality and Hunger in Europe and America." Working Paper no. 16 (September), NBER, Cambridge, MA. 1991. "New Sources and New Techniques for the Study of Secular Trends in Nutritional Status, Health Mortality and the Process of Aging." Working Paper no. 26 (May), NBER, Cambridge, MA.

Foster, Andrew, and Nizam Kahn. 2000. "Equilibrating the Marriage Market in a Rapidly Growing Population: Evidence from Rural Bangladesh.” Home Pages Working Paper no. 80 (August), Univ. Pennsylvania.

Friedman, Mark I., Israel Ramirez, Charles R. Bowden, and Michael G. Tordoff. 1990. "Fuel Partitioning and Food Intake: Role of Mitochondrial Fatty Acid Transport." American J. Physiology-Regulatory, Integrative and Comparative Physiology 258 (January): R216-R221.

Gedda, Luigi, and Gianni Brenci. 1975. "Twins as a Natural Test of Chronogenetics." Acta Geneticae Medicae et Gemallologiae 24 (1-2): 15-30.

Gellert, Ronald J. 1978. "Kepone, Mirex, Dieldrin and Aldrin: Estrogenic Activity and the Induction of Persistent Vaginal Estrus and Anovulation in Rats Following Neonatal Treatment." Environmental Res. 16 (February): 131-38.

. 1995. "Uterotrophic Activity of Polychlorinated Biphenyls (PCB) and Induction of Precocious Reproductive Aging in Neonatally Treated Rats." Environmental Res. 16 (February): 123-30.

Golub, Mari S., Casey E. Hogrefe, Stacy L. Germann, and Christopher P. Jerome. 2004. "Endocrine Disruption in Adolescence: Immunologic, Hematologic, and Bone Effects in Monkeys.” Toxicological Sci. 82 (December): 598-607.

Graber, Julia A., Jeanne Brooks-Gunn, and Anne C. Petersen. 1996. "Pubertal Processes: Methods, Measures, and Models." In Transitions through Adolescence: Interpersonal Domains and Context, edited by Julia A. Graber, Jeanne BrooksGunn, and Anne C. Petersen. Hillsdale, NJ: Erlbaum.

Gray, Leon Earl, Jr., and Joseph S. Ostby. 1995. "In Utero 2, 3, 7, 8-Tetrachlorodibenzp-Pdioxin (TCDD) Alters Reproductive Morphology and Function in Female Rat Offspring." Toxicology and Appl. Pharmacology 133 (August): 28594.

Halli, Shiva S. 2003. "Marriage Patterns in Rural India: Influence of Sociocultural Context.” Manuscript, Univ. Manitoba.

Herrinton, Lisa J., and Gail Husson. 2001. "Relation of Childhood Height and Later Risk of Breast Cancer." American. J. Epidemiology 154 (October): 618-23.

Howdeshell, Kembra L., and Frederick S. vom Saal. 1997. "Prenatal Exposure to an Environmentally Relevant Dose of Bisphenol A Accelerates Puberty in Female Mice." In Estrogens in the Environment IV. Arlington, VA: Nat. Insts. Health and Nat. Inst. Environmental Health Services.

Howenstein, M. J., E. A. Meyers, K. A. Russell, and H. I'Anson. 2000. “The Role of Fatty Acid Metabolism in Signaling the Onset of Puberty in Prepubertal Female Rats." Washington and Lee J. Sci. 1 (Spring): 125-29.

I'Anson, H., D. L. Foster, G. R. Foxcroft, and P. J. Booth. 1991. "Nutrition and Reproduction." In Oxford Reviews of Reproductive Biology, vol. 13, edited by S. R. Milligan. Oxford: Oxford Univ. Press.

ICRW (International Center for Research on Women). 2003. "ICRW Policy Advisory on Child Marriage." Internat. Centre Res. on Women, Washington, DC, http://www.icrw.org/docs/childmarriage0803.pdf. 
Jensen, Robert, and Rebecca Thornton. 2003. "Early Female Marriage in the Developing World." In Gender, Development and Marriage, edited by Caroline Sweetman. Oxford: Oxfam GB.

Joshi, Shareen. 2004. "Female Household-Headship in Rural Bangladesh: Incidence, Determinants and Impact on Children's Schooling." Manuscript, Yale Univ.

Kaprio, Jaakko, Rimpela Arja, Winter Torsten, Richard Viken, and Richard J. Rose. 1995. "Common Genetic Influences on BMI and Age at Menarche." Human Biology 67 (October): 739-53.

Kennedy, G. C. 1957. "The Development with Age of Hypothalmic Restraint upon the Appetite of the Rat." J. Endocrinology 16 (November): 9-17.

Kennedy, G. C., and J. Mitra. 1963. "Body Weight and Food Intake as Initiating Factors for Puberty in the Rat." J. Physiology 166 (May): 408-18.

Khandker, Shahidur R., and Hussain A. Samad. 1995. "Education Achievements and School Efficiency in Rural Bangladesh.” Bangladesh Development Studies 23 (1-2), art. 1. http://www.bids-bd.org/about/bds-list03.html.

Kimmel, Carol A., Lester D. Grant, Carol S. Sloan, and Beth C. Gladen. 1980. "Chronic Low-Level Lead Toxicity in the Rat." Toxicology and Appl. Pharmacology 56 (October): 28-41.

Komura, H., et al. 1998. "Effects on Pubertal Growth in Rats Exposed to Lead Perinatally or Continuously through Development." J. Toxicology and Environmental Health 53 (February): 327-41.

Kramer, P., and H. M. Meijs-Roelofs. 1982. "Retardation of First Ovulation in Pubertal Rats after Treatment with 5 Alpha-Androstane-3 Alpha, 17 Beta-Diol or Its 3 Beta-Epimer." J. Endocrinology 92 (January): 31-35.

Krogman, Wilton M. 1972. Child Growth. Ann Arbor: Univ. Michigan Press.

Laws, Susan C., James M. Ferrell, Tammy E. Stoker, Judith Schmid, and Ralph L. Cooper. 2000. "The Effects of Atrazine on Female Wistar Rats: An Evaluation of the Protocol for Assessing Pubertal Development and Thyroid Function." Toxicological Sci. 58 (December): 366-76.

Legros, Patrick, and Andrew F. Newman. 2002. "Monotone Matching in Perfect and Imperfect Worlds." Rev. Econ. Studies 69 (October): 925-42.

Lehrer, Steven. 1986. "Rats on 22.5-Hr Light:Dark Cycles Have Vaginal Opening Earlier than Rats on 26-Hr Light:Dark Cycles." J. Pineal Res. 3 (October): 37578.

Livson, Norman, and David McNeill. 1962. "The Accuracy of Recalled Age of Menarche." Human Biology 34 (September): 218-21.

Mahmud, Simeen. 2003. Female Secondary Stipend Project in Bangladesh: A Critical Assessment. Dhaka: Inst. Development Studies, http://portal.unesco.org/ education/ev.php?URL_ID $=25755$.

Mann, D. R., and T. M. Plant. 2002. "Leptin and Pubertal Development." Seminars Reproductive Medicine 20 (2): 93-102.

Martorell, Raynalde. 1993. "Enhancing Human Potential in Guatemalan Adults through Improved Nutrition in Early Childhood.” Nutrition Today 28 (JanuaryFebruary): 6-14.

Martorell, Raynalde, and Jean-Pierre Habicht. 1986. "Growth in Early Childhood in Developing Countries." In Human Growth, vol. 3, edited by Frank Falkner and James M. Tanner. New York, Plenum.

McLachlan, J. A., and R. L. Dixon. 1977. "Toxicologic Comparison of Experimental and Clinical Exposure to Diethylstilbestrol during Gestation." In Advances in Sex Steroid Hormone Research, vol. 3. Baltimore: University Park Press.

Merry, B. J., and Anne M. Holehan. 1979. "Onset of Puberty and Duration of 
Fertility in Rats Fed a Restricted Diet." J. Reproduction and Fertility 57 (November): 253-59.

Messer, Neal A., and Helen I'Anson. 2000. "The Nature of the Metabolic Signal Capable of Triggering the Onset of Puberty in Food-Restricted, Prepubertal Female Rats." Physiology and Behavior 68 (January): 377-82.

Meyer, Joanne M., Lindon J. Eaves, Andrew C. Heath, and Nicholas G. Martin. 1991. "Estimating Genetic Influences on the Age at Menarche: A Survival Analysis Approach." American J. Medical Genetics 39 (May): 148-54.

Monosson, Emily, William R. Kelce, Christy Lambright, Joseph Ostby, and L. Earl Gray Jr. 1999. "Peripubertal Exposure to the Antiandrogenic Fungicide, Vinclozolin, Delays Puberty, Inhibits the Development of Androgen-Dependent Tissues, and Alters Androgen Receptor Function in the Male Rat." Toxicology and Indus. Health 15 (January-March): 65-79.

Mucignat-Caretta, Carla, Antonio Caretta, and Andrea Cavaggioni. 1995. "Acceleration of Puberty Onset in Female Mice by Male Urinary Proteins." J. Physiology 486 (July): 517-22.

Must, A., et al. 2002. "Recall of Early Menstrual History and Menarcheal Body Size: After 30 Years, How Well Do Women Remember?" American J. Epidemiology 155 (April): 672-79.

Nahar, Quamrun, et al. 1999. Strategies to Meet the Health Needs of Adolescents: A Review. Special Publications no. 91. Dhaka: Internat. Centre Diarrhoeal Diseases Res., Operations Res. Project, Health and Population Extension Div.

Nazian, S. J., and B. E. Piacsek. 1976. "Vaginal Opening and Early Estrous Cycles in Rats Raised at a Low Ambient Temperature.” J. Experimental Zoology 198 (October): 13-16.

Nelson, James F., Katarzyna Karelus, Leda S. Felicio, and Thomas E. Johnson. 1990. "Genetic Influences on the Timing of Puberty in Mice." Biological Reproduction 42 (April): 649-55.

Palmert, Mark R., and Paul A. Boepple. 2001. "Variation in the Timing of Puberty: Clinical Spectrum and Genetic Investigation." J. Clinical Endocrinology and Metabolism 86 (June): 2364-68.

Pellerin-Massicotte, Jocelyne, Guy R. Brisson, Celine St.-Pierre, Pierre Rioux, and Denis Rajotte. 1987. "Effect of Exercise on the Onset of Puberty, Gonadotropins, and Ovarian Inhibin.” J. Appl. Physiology 63 (September): 1165-73.

Plant, Tony M., and Andrea R. Durant. 1997. "Circulating Leptin Does Not Appear to Provide a Signal for Triggering the Initiation of Puberty in the Male Rhesus Monkey (Macaca Mulatta)." Endocrinology 138 (October): 4505-8.

Rahman, M. Omar, et al. 1999. The 1996 Matlab Health and Socioeconomic Survey: Overview and User's Guide. DRU-2018/1-NIA. Santa Monica, CA: RAND.

Ronnekleiv, Oline K., Sergio R. Ojeda, and Samuel M. McCann. 1978. "Undernutrition, Puberty and the Development of Estrogen Positive Feedback in the Female Fat." Biology of Reproduction 19 (September): 414-24.

Schneider, Jill E., Angela J. Hall, and George N. Wade. 1997. "Central vs. Peripheral Metabolic Control of Estrous Cycles in Syrian Hamsters. I. Lipoprivation." American J. Physiology—Regulatory, Integrative and Comparative Physiology 272 (January): R400-R405.

Schultz, T. Paul. 1987. "Education Investments and Returns in Economic Development." Discussion Paper no. 528, Econ. Growth Center, Yale Univ.

Scott, E. C., and F. E. Johnston. 1985. "Science, Nutrition, Fat, and Policy: Tests of the Critical-Fat Hypothesis." Current Anthropology 26 (4): 463-73.

Shahabuddin, A. K. M., et al. 2000. "Adolescent Nutrition in a Rural Community in Bangladesh.” Indian J. Pediatrics 67 (February): 93-98. 
Shimer, Robert, and Lones Smith. 2000. "Assortative Matching and Search." Econometrica 68 (March): 343-69.

Sklad, Maciej. 1977. "The Rate of Growth and Maturing in Twins." Acta Genetica Medicae et Gemellologiae 26 (3-4): 221-37.

Stathopolu, Eleni, J. Antony Hulse, and David Canning. 2003. "Difficulties with Age Estimation of Internet Images of Southeast Asians." Child Abuse Rev. 12 (January/February): 46-57.

Stoker, Tommy E., Louise G. Parks, L. Earl Gray, and Ralph L. Cooper. 2000. "Endocrine Disrupting Chemicals: Prepubertal Exposures and Effects on Sexual Maturation." Critical Revs. Toxicology 30 (March): 197-252.

Toppari, Jorma, John Larsen, and Peter Christiansen. 1996. "Male Reproductive Health and Environmental Xenoestrogens." Environmental Health Perspectives 104 (suppl. 4; August): 741-803.

Vandenbergh, John G. 1969. "Male Odor Accelerates Female Sexual Maturation in Mice." Endocrinology 84 (March): 658-60.

Vandenbergh, John G., Jeffrey A. Whitsett, and John R. Lombardi. 1975. "Partial Isolation of a Pheromone Accelerating Puberty in Female Mice." J. Reproductive Fertility 43 (June): 515-23.

Vasallo, M. A., Karnon Chartisathian, E. J. Dougherty, K. G. Kitchens, J. A. Markham, and Helen I'Anson. 1998. "Does a Reduction in Glucose Availability Suppress Estrous Cycles in Adult Female Rats?” Biological Reproduction 58 (suppl. 1): 136.

Wade, George N., and Jill E. Schneider. 1992. "Metabolic Fuels and Reproduction in Female Mammals." Neuroscience and Biobehavioral Revs. 16 (2): 235-72.

Walters, Laura M., Arthur W. Rourke, and Victor P. Eroschenko. 1993. "Purified Methoxychlor Stimulates the Reproductive Tract in Immature Female Mice." Reproductive Toxicology 7 (6): 599-606.

Whitney, Andrew C., and Ann S. Clark. 2001. "Effects of Acute Stanozolol Treatment on Puberty in Female Rats." Biology of Reproduction 64:1460-65.

Whitten, Patricia L. 1993. "A Phytoestrogen Diet Induces the Premature Anovulatory Syndrome in Lactationally Exposed Female Rats.” Biology of Reproduction 49:1117-21.

Widdowson, Elsie M., and Robert A. McCance. 1960. "Some Effects of Accelerating Growth I. General Somatic Development.” Proc. Royal Soc. London, ser. B, 152 (May 17): 188-206.

Wilen, Richard, Charles H. Bastomsky, and Frederick Naftolin. 1981. "Control of Puberty in Female Rats: The Effect of PTU-Induced Hypothyroidism and Systematic Undernutrition." Pediatric Res. 15 (2): 169-71.

Withuhn, Thomas F., Kristen M. Kramer, and Bruce S. Cushing. 2003. "Early Exposure to Oxytocin Affects the Age of Vaginal Opening and First Estrus in Female Rats." Physiological Behavior 80 (1): 135-38.

Yamada, K., R. Itoh, and A. Ohta. 1989. "Influence of Pyrazine Derivatives on the Day of Vaginal Opening in Juvenile Female Rats." Japanese J. Pharmacology 49 (4): 529-30. 